March 2015

\title{
"Price Transmission in Food Chains: The Case of the Dairy Industry
}

Céline Bonnet, Tifenn Corre, and Vincent Réquillart 


\title{
Price Transmission in Food Chains: The Case of the Dairy Industry ${ }^{1}$
}

\author{
Céline Bonnet ${ }^{2}$, Tifenn Corre $^{3}$, and Vincent Réquillart ${ }^{4}$
}

\section{Introduction}

On average, the share of household expenditure on food in Europe was about 13\% in 2011 (Eurostat data). There is, however a large variation in expenditure shares across EU countries. For example, the share of household expenditure on food in 2011 was $10.2 \%$ in Ireland, $13.7 \%$ in France, and $18.5 \%$ in Poland. More importantly, because food is a staple good, there is a large variation across income levels. Thus, whereas the average percentage of household expenditure on food was $16.8 \%$ in 2005 , it was $22.2 \%$ for the first income quintile and $13.0 \%$ for the fifth quintile. ${ }^{5}$ In a context in which a significant portion of the EU population is concerned about food price inflation, this raises the question of how shocks in agricultural prices are transmitted to consumers’ prices. As shown by Bukeviciute, Dierx and Ilzkovit (2009), following the peak of agricultural commodity prices in 2007-2008, food price inflation in the EU has displayed considerable discrepancies across countries. For example, the elasticity of consumer food prices to producer food prices was about $15-20 \%$ in the Eurozone on average but reached 30\% in Sweden. Lloyd et al. (2013) points out that the heterogeneity of price transmission in the EU is linked to the strong heterogeneity of how the food chain functions in the different member states and for the different food chains.

\footnotetext{
${ }^{1}$ This paper is part of the `Transparency of Food Pricing' (TRANSFOP) project funded by the European Commission, Directorate General Research - Unit E Biotechnologies, Agriculture, Food. Grant Agreement No.KBBE-265601-4-TRANSFOP. We thank Olivier de Mouzon for his assistance in programming. Any remaining errors are ours.

${ }^{2}$ Toulouse School of Economics (INRA, GREMAQ), 21 Allée de Brienne, F-31000 Toulouse France, Tel: +33(0)5 611285 91, cbonnet@toulouse.inra.fr

${ }^{3}$ Toulouse School of Economics (INRA, GREMAQ), 21 Allée de Brienne, F-31000 Toulouse France, tifenn.corre@tse-fr.eu

${ }^{4}$ Toulouse School of Economics (INRA, GREMAQ, IDEI), 21 Allée de Brienne, F-31000 Toulouse France, Tel: +33 (0)5 611286 07, Vincent.Requillart@toulouse.inra.fr

${ }^{5}$ http://epp.eurostat.ec.europa.eu/portal/page/portal/household_budget_surveys/Data/database (accessed 12 April, 2014).
} 
Due to the Common Agricultural Policy (CAP) reforms in the 2000s, the EU prices of agricultural products now experience larger variations than in the past. These reforms dramatically changed the way in which farmers' incomes are supported in the EU. Whereas support was mostly administered through price support in the 1990s, most of the support is now provided through direct payments. Thus, in 1990, price support represented $84 \%$ of the support in the EU, whereas it was only $12 \%$ in $2011 .^{6}$ Moreover, because the tools to avoid large price decreases were mainly dismantled, prices can experience greater decreases than in the past. As an example, the milk price dropped by $30 \%$ in 2009 , whereas this did not happen in the 15 previous years. In addition, EU prices of agricultural products are now more connected to world prices and have been since some of the forms of protection that isolated the EU agricultural markets from the rest of the world were removed. Thus, the Producer Nominal Protection Coefficient, which is the ratio of the average price received by producers at the farm gate to the border price, measured at the farm gate, was 1.48 in 1990 and had fallen to 1.03 in 2011.

A standard way to analyse price transmission along the food supply chain is to base the analysis on time series. For example, Hassouneh et al. (2013) developed a systematic analysis of price transmission in the EU. They documented the heterogeneity of price transmission among countries and commodities. They found that producer prices tend to adjust to deviations from equilibrium prices at a faster speed than consumer prices. They also found that some commodities (eggs, poultry, and pork) respond more quickly to deviations from the long-run equilibrium price compared to other commodities (beef, dairy products, wheat products). Moreover, they found that an increase in the degree of a country's specialisation in producing a certain food product reduces the speed of producer price adjustment to market price disequilibriums. In the case of dairy markets in Germany, Loy et

\footnotetext{
${ }^{6}$ OECD PSE database, https://stats.oecd.org/Index.aspx?DataSetCode=MON20123_1 (accessed 15 April,
} 2014). 
al. (2014) showed that the price adjustment of private labels (PLs) was much faster than that of national brands (NBs). On the whole, these methods allow for the characterization of price transmission in different markets, but the main determinants of food price transmission remain unclear (for a recent survey, refer to Frey and Manera, 2007).

An alternative way to analyse price transmission is to use a structural model in order to better understand the behaviour of the food supply chain and to deduce the implications for price transmission (recent contributions include Kim and Cotterill, 2008; Nakamura and Zerom, 2010, Bonnet et al., 2013). This methodology is appropriate in the case of concentrated markets in which firms are able to strategically set up prices. This is the case in numerous food supply chains, which typically consist of large firms with significant market power. In the food industry, the market share of the top three manufacturers is frequently greater than $50 \%$ and the top five retailers now account for over $50 \%$ of the grocery market in many EU countries (McCorriston, 2013). Food supply chains are therefore frequently composed of a chain of oligopolies.

In a context of perfect competition, cost pass-through is lower than or equal to 1 and depends on the elasticities of supply and demand. ${ }^{7}$ In a context of imperfect competition, cost pass-through also depends on markup adjustments. In particular, the literature on taxation under conditions of imperfect competition has shown that the cost pass-through might be less than or greater than 1 depending on the curvature of the demand function (Stern, 1987; Delipalla and Keen, 1992; Anderson , de Palma and Kreider, 2001).

For example, Nakamura and Zerom (2010) studied the US coffee industry and reported a long-run pass-through of coffee commodity prices to retail prices of 0.92. Recently Bonnet and Réquillart (2013) found that the cost pass-through in the French soda market is 1.16, on average. Hellerstein (2008) showed that markup adjustments at the manufacturer and retailer

\footnotetext{
${ }^{7}$ Following Kim and Cotterill (2008), we assume that the "cost pass-through rate is defined as the proportion of a change in input cost that is passed through to the final price of the product".
} 
levels play an important role in explaining the pass-through of cost changes in the US beer industry. Overall, these papers suggest that firms should strategically adjust their markups when facing a change in their input costs. Moreover, as shown by Bonnet et al. (2013), the pass-through rate for upstream cost shocks to downstream retail prices depends on the form of the contracts between manufacturers and retailers. This literature suggests that to assess price transmission along a particular food supply chain, it is necessary to consider key characteristics such as the structure of the chain, consumers' substitution patterns, and the type of contracts linking manufacturers and retailers.

In this chapter, we develop a structural econometric model that allows for the assessment of the price transmission of a cost change, taking into account horizontal and vertical interactions between manufacturers and retailers. We follow the methodology developed by Berto Villas-Boas (2007) and Bonnet and Dubois (2010) and recently used by Bonnet and Réquillart (2013). This methodology mainly consists of a three-step analysis. In the first step, a demand model is designed and estimated. Then, in the second step, given the demand estimates, price-costs margins are computed for a set of contracts between food manufacturers and retailers. For each type of contract, the first-order conditions for profit maximization allow for definition of structural equations that define price-cost margins in the chain. This step also includes the selection of the model of vertical relationships that best fits the data. Finally, the third step consists of using the selected model to perform simulations.

We apply this methodology to two dairy markets: the fluid milk market and the dairy desserts market. We choose those industries for many reasons. First, the milk industry as a whole is one of the main food industries in Europe, comprising 14\% of the annual turnover of all food industries (Food Drink Europe, 2014). Second, it encompasses final products that present different characteristics in terms of concentration, PL penetration, and cost of raw milk in the production process. Third, as explained above, the farm milk price has 
experienced large price variations in the recent past. We show that the pass-through for NBs is greater than 1 in the fluid milk market whereas it is less than 1 in the dairy desserts market. Therefore, depending on the market, firms will overshift or undershift cost changes. It should be noted that in both markets, we found that PLs fully transmit the cost change (the pass-through is very close to 1 for all PLs whatever the market considered).

This chapter is organised as follows. Section 2 presents the data and provides descriptive statistics about dairy markets. Section 3 describes the model and methods used to analyse consumers' demand and to infer the vertical relationships between manufacturers and retailers. Section 4 discusses the results relative to the demand, to the vertical relationships in both industries, relative to cost pass-through. Finally, Section 5 concludes.

\section{French Dairy Market and Data}

Before 2006, the farm milk price in France was rather predictable (Figure 1). From 1990 to 2001, the average annual price was roughly constant and the monthly price followed a clear seasonal cycle, with high prices in winter and lower prices in summer. From 2001 to 2007, the seasonal pattern did not change but the average annual price followed a negative trend that is easily explained by the reform of the dairy sector, which consisted of lowering support prices and increasing quotas. ${ }^{8}$ Since 2007 , the milk price has experienced a period of higher volatility, with a peak in 2008 and a low in 2009, which is explained by the removal of the main tools that were used to support the farm milk price. It is also explained by the growing influence of world market prices on EU prices. In this study, we focus on the last period (2006-2009) to analyse, in the context of higher volatility, how changes in the farm milk price are transmitted through to retail prices.

\footnotetext{
${ }^{8}$ In the framework of the Luxembourg reform (2003), the intervention price for butter falls by $25 \%$ in four steps from 2004 to 2007 and the intervention price for skimmed milk powder falls by $15 \%$ in three steps from 2004 to 2006. For an analysis of the milk dairy reform, refer to Bouamra, Jongeneel and Réquillart (2008).
} 


\section{INSERT FIGURE 1}

To investigate the impact of raw milk price changes on consumer prices, we study two final markets: the dairy desserts market and the fluid milk market. As explained in the introduction, we choose these markets because their structure, the importance of differentiated products, the importance of PLs, and the cost structure differ significantly. In particular, according to the 'Observatoire des prix et des marges', the raw milk cost is about one-third of the consumer price for liquid milk and one-sixth for yoghurt (a type of dairy dessert) and it is likely to be much less for more processed desserts such as cream desserts. ${ }^{9}$ In the case of dairy desserts (Figure 2), there is a link between retail and farm milk prices, but for non fat-products, the link seems to be smaller than it is for regular products. For example, for yoghurts, the correlation between the raw milk price and the retail price of yoghurts is 0.75 for standard yoghurt and it is -0.01 for non-fat yoghurts. In the case of the fluid milk market, there is a clear link between the evolution of retail prices changes and the evolution of the raw milk price. The changes in the skimmed milk price are smaller than for semi-skimmed milk and whole milk, but the general evolution of prices suggests a strong link between farm and retail prices.

\section{INSERT FIGURE 2}

\subsection{Data}

To conduct the analysis of both sectors, we use consumer panel data collected by Kantar WorldPanel, a French representative survey of 20,000 households, over a four-year period (2006-2009). This survey records information about every purchase of food products (e.g.,

\footnotetext{
${ }^{9}$ https://observatoire-prixmarges.franceagrimer.fr/resultats/Pages/ResultatsFilieres.aspx?idfiliere=6 (accessed 12 May, 2014).
} 
quantity, price, brand, characteristics of goods, and the retailer from which products are purchased) for each household in the panel. The data only cover household purchases for home consumption, and thus out-of-home consumption is excluded. It should be noted, however, that home consumption dominates, as home consumption accounts for $86.5 \%$ of total consumption of dairy desserts and $95 \%$ of total consumption of fluid milk (AFSSA, 2009)..$^{10}$

From a consumer perspective, a product is the combination of a brand and a retailer. Thus, brand 1 bought at retailer 1 is different from brand 1 purchased at retailer 2 . This distinction allows us to analyse vertical contracts between manufacturers and retailers as well as different price strategies between retailers. As shown by Steiner (1993), the balance of power between manufacturers and retailers within a chain is strongly related to the loyalty of consumers towards brands or stores. It is therefore important to characterise a purchase in terms of both the brand purchased and the retailer from which the consumer purchased the product. Retailers are grocery store chains that differ by both the size of their outlets and the services they provide to consumers. We consider the top five retailers that operate in the French retail sector (three of them are characterised by large outlets and the two other have intermediate sized outlets) and two aggregates. One aggregate includes the discounters, which have small to intermediate sized outlets and provide basic services only. The other aggregate comprises the remaining retailers. All these retailers are national chains present throughout France. Consumers from the different regions in France are presented with the same assortment of products when they visit a given retailer. ${ }^{11}$ We now provide specific information on brands for the two markets.

\footnotetext{
10 EtudeIndividuelle des Consommations Alimentaires INCA2. http://www.anses.fr/sites/default/files/documents/PASER-Ra-INCA2.pdf (accessed 6 June, 2014).

11 This is true for the NBs we consider, which are the main ones. It might be the case that in some small outlets, the assortment is reduced, but we do not have the necessary information.
} 


\subsection{The market for dairy desserts}

Dairy desserts are a part of the dessert market. We consider five product categories of dairy desserts and to deal with the substitution that occurs with other desserts, we define an ‘outside option’ comprised of pastries, ice creams, and fruits. The fiveproduct categories are defined as follows. First, we define three segments of dairy desserts: yoghurts (plain, flavoured, or fruit yoghurts), cottage cheeses, and other dairy desserts such as cream desserts, creamy rice puddings, mousses, or custards, for example. In addition, for the first two segments, we distinguish low-fat products from regular products. We thus have five product categories. On the whole, the five product categories represent about $53 \%$ of the entire market. ${ }^{12}$ According to our sample, Danone, Yoplait, and Nestlé are the three main manufacturers within the market for dairy desserts. They represent $42 \%$ of purchases of these products, whereas the market share of PLs is 49\%. The remaining $9 \%$ of the market is covered by other manufacturers producing NBs. These products are gathered in an aggregate. To assess price formation at the brand level, we consider the four main brands produced by Danone (Activia, Danette, Taillefine, and Gervais), the main brand for Yoplait (Panier de Yoplait), and the main brand for Nestlé (La laitière). We also define three aggregates, each one including brands of Danone, Yoplait, and Nestlé other than those described previously. Finally, we consider five PLs, one for each of the five product categories previously described. Given this segmentation by brands and by type of products, we finally have 23 brands with 18 NBs and five PLs. Because each of these products is available in each of the seven retailers, we thus consider 159 differentiated products that compete in the market for dairy desserts. ${ }^{13}$

\footnotetext{
${ }^{12}$ The market share of a product (brand $\mathrm{x}$ retailer) is defined as the ratio of the sum of the quantities of the selected brand purchased at the selected retailer during a period of three months and the sum of quantities of all brands purchased at all of the retailers during the same period in the whole market, which includes dairy desserts, fruits, ice-creams, and pastries in the case of dairy desserts, and all kinds of milk in the case of fluid milk.

${ }^{13}$ One of the retailers only distributes 21 products rather than 23.
} 


\section{INSERT TABLE 1}

The average price of dairy desserts is $€ 2.27$ per kilogram (Table 1 ). ${ }^{14}$ The average prices of regular yoghurts, regular cottage cheeses, and other dairy desserts are $€ 1.94, € 2.42$, and $€ 2.96$ per kilogram, respectively. The main market segment is yoghurt (58\% of dairy desserts purchases). Regular products dominate the market since they represent roughly 85\% of all dairy desserts purchases. On average, for each product category, NBs’ prices are 50\% higher than PLs' prices. Yoghurts are the cheapest products, for both types of brands, followed by cottage cheese and then other dairy desserts. On average, diet yoghurts are sold at a higher price than the regular ones, whereas we observe the opposite for the cottage cheeses. This is explained by the fact that diet cottage cheeses are PLs only. Among NBs, there is some heterogeneity in the prices (Table 7 in the Appendix). This heterogeneity might be linked to the heterogeneity in product characteristics but this also reflects strategic pricing by firms.

All brands are available in every retail chain, except in retailer 7, which mainly sells PLs, which represent $80 \%$ of its sales (Table 8 in the Appendix). Retailers 1 to 5 choose similar prices. The average price in these retailers is mainly explained by the relative shares of NBs and PLs sold by each retailer. The higher the share of PLs sold by a retailer, the lower the average price in this retailer. Retailer 6 is between $10 \%$ and $15 \%$ more expensive than retailers 1 to 5 , whereas retailer 7 is significantly cheaper. Retailer 7 is the aggregate of discounters, which generally offer fewer products with lower service levels. Indeed, prices for both NBs and PLs are lower in retailer 7 than they are in the other retailers.

${ }^{14}$ The average is computed over the 159 products and the 16 periods (trimesters). 


\subsection{The market for fluid milk}

In the case of fluid milk, the market is less diverse and there is almost no substitution between liquid milk and other beverages. For example, Bouamra et al. (2008) estimated a price elasticity of -0.15 for fluid milk in France. They also found non-significant cross-price elasticities between fluid milk and dairy desserts. In some studies, mostly examining the US market, fluid milk is a substitute for soft drinks. Allais, Bertail and Nichele (2010), however, found that in France milk and soft drinks are not substitutes. Thus, econometric analysis suggests that the demand for liquid milk in France is highly inelastic and that substitution with other products is very limited. Therefore, in this analysis, we define the market as the fluid milk market. The bulk of the market comprises cow milk (98.6\%), with the remaining part being soy milk and goat milk. These two products are considered as the 'outside' option. Given the very small market share of these two products, it means that the market for cow milk will be considered as being inelastic. Relative price changes will mainly induce substitution between brands of liquid cow milk rather than substitutions with soy milk or goat milk. We define three segments for the cow milk market: skimmed, semi-skimmed, and whole milk. We select the main NBs. In our sample, Sodiaal and Lactalis are the two main manufacturers in the fluid milk market. Sodiaal has one brand (Candia), whereas Lactalis has two different brands (Lactel and Bridel). We also consider an aggregate NB produced by 31 smaller producers. For each of these four NBs, there are three products that are differentiated on the basis of their fat content. It should be acknowledged that for each brand, the market share of the semi-skimmed product is dominant. Considering the entire market, semi-skimmed milk has about $86 \%$ of the market (Table refTab-StatDes-byCat-Milk). Finally, we define three PLs, one for each type of product. PLs dominate this market, with a market share as high as $62 \%$. 


\section{INSERT TABLE 2}

The average price over all products and all periods is $€ 0.67$ per litre (Table 2). The average price of whole milk is higher than that of skimmed and semi-skimmed milk, which have similar average prices. When differentiating PL and NB prices, however, the picture is a little bit different. Thus, forPLs, skimmed milk is cheaper than semi-skimmed milk, which is cheaper than whole milk. This is not true for NBs, as the price of semi-skimmed milk is significantly lower than the price of skimmed milk and whole milk. This is a clear indication of strategic pricing by firms. Due to the strong competition from PLs in the main market segment (semi-skimmed milk), NB prices are close to PL prices (NB prices are 'only’ about 15\% higher). In respect of the other segments, the difference in prices between NBs and PLs is much higher (NBs are about 50\% more expensive than PLs). As shown in Table 9 (in the Appendix), among the NBs, there is some heterogeneity in prices. In particular, prices of the main NBs (brands 1 to 9) are higher than those of the aggregate NBs (brands 10 to 12). This certainly results from the market power and strategic pricing of the firms producing the main NBs.

As compared to the dairy desserts market, the market share of PLs in the fluid milk market is higher and the relative price difference between PLs and NBs is lower. A possible interpretation is that in the fluid milk market, consumers consider that the quality difference between PLs and NBs is not high, whereas they consider that there are still some differences in quality in the dairy desserts market. Then, in the fluid milk market, NBs cannot sustain higher prices (than PLs) and maintain significant market shares, whereas this is somewhat possible in the dairy desserts market.

All brands are available in every retail chain, except in retailer 2, in which a product is missing, and in retailer 7, which mainly sells PLs (Table 10 in the Appendix). Retailers 1 to 5 choose prices that are quite similar on average. Despite the fact that PLs have almost the 
same prices in the different retailers, we note a larger difference between the prices of NBs. Retailer 6 and, to a lesser extent, retailer 3, sells the NB products at a higher price than the other retailers. Retailer 7 is still a special case in this market, with lower prices for both NBs and PLs than in the other retailers.

\section{Models and Methods}

To analyse strategic pricing in the food chain, we follow a general methodology that was recently developed to analyse vertical relationships between manufacturers and retailers (e.g. Berto Villas-Boas, 2007; Bonnet and Dubois, 2010). We consider a demand model for each market to obtain the price elasticities of demand for every product in the market (that is, 159 products for the dairy desserts market and 103 products for the liquid milk market). The model needs to be as flexible as possible, so we opt for a random coefficients logit model (Berry, Levinsohn and Pakes, 1995; McFadden and Train, 2000). Strategic pricing in the supply chain can be modified by the nature of the contracts between firms in the industry or by the vertical restraints considered. To deal with this issue, we design alternative models for the vertical relationships between the processors and the retailers. Based on the first-order conditions and estimates of demand, we are able to compute the price-cost margins for each product, from which we deduce the total marginal costs. To choose the vertical relationship model that best fits the data, we estimate a cost equation for each supply model and we use a non-nested Rivers and Vuong (2002) test to select the best one among all the alternatives. Finally, using the selected model, we simulate the impact of a shock to the raw milk price on retail prices. In the following, we provide a brief summary regarding the main assumptions and methods. More extensive explanations regarding the details of the methodology can be found in Bonnet and Dubois (2010) and Bonnet and Réquillart (2013). 


\subsection{The demand model : A random coefficients logit model}

We use a random coefficients logit model to estimate the demand model and the related price elasticities. The indirect utility function $V_{i j t}$ for consumer $i$ buying product $j$ in period $t$ is given by:

$$
V_{i j t}=\beta_{b(j)}+\beta_{r(j)}+\alpha_{i} p_{j t}+\beta X_{j}+\varepsilon_{i j t}
$$

where $\beta_{b(j)}$ and $\beta_{r(j)}$ are, respectively, brand and retailer fixed effects that capture the (time invariant) unobserved brand and retailer characteristics, $p_{j t}$ is the price of product $j$ in period $t, \alpha_{i}$ is the marginal disutility of the price for consumer $i, X_{j}$ is a vector of product characteristics, and $\beta$ is the vector of associated parameters. For dairy desserts, $X_{j}=\left(C_{j}, D_{j}, l_{j}\right)$ is composed of three dummies for cottage cheeses, dairy desserts, and diet products, respectively. ${ }^{15}$ The associated coefficients represent the taste for cottage cheese and dairy desserts as compared to the taste for yoghurts and the taste for diet products as compared to the taste for regular products. For the fluid milk market, we chose two dummies for the fat category, $X_{j}=\left(S_{j}, W_{j}\right)$, for skimmed milk and whole milk, respectively. ${ }^{16}$ The associated coefficients capture the taste for these fat contents as compared to the taste for semi-skimmed milk. Finally, $\varepsilon_{i j t}$ is an unobserved individual error term.

In both markets, we assume that $\alpha_{i}$ varies across consumers. Indeed, consumers can have a different price disutility. We assume that the parameter has the following specification:

$$
\alpha_{i}=\alpha_{N B_{j(i)}}+\alpha_{P L_{j(i)}}+\sigma v_{i}
$$

where $\alpha_{N B_{j(i)}}$ and $\alpha_{P L_{j(i)}}$ are the mean price sensitivities when the product bought by the

\footnotetext{
${ }^{15} C_{j}$ takes the value of 1 if product $j$ is a cottage cheese product and 0 otherwise; $D_{j}$ takes the value of 1 if product $j$ is another dairy dessert and 0 otherwise; $l_{j}$ takes the value of 1 if product $j$ is a diet product and 0 otherwise.

${ }^{16} S_{j}$ takes the value of 1 if product $j$ is a skimmed milk product and 0 otherwise; $W_{j}$ takes the value of 1 if product $j$ is whole milk product and 0 otherwise.
} 
consumer is respectively an NB or a PL, $v_{i}$ captures the unobserved consumer's characteristics, and $\sigma$ measures the dispersion of the unobserved heterogeneity from the mean price sensitivity. We assume a parametric distribution for $v_{i}$ denoted by $P_{v}($.$) and P_{v}$ is independently and identically distributed as a standard normal distribution.

We can then break down the indirect utility into a mean utility:

$$
\delta_{j t}=\beta_{b(j)}+\beta_{r(j)}+\left(\alpha_{N B_{j(i)}}+\alpha_{P L_{j(i)}}\right) p_{j t}+\beta X_{j}+\xi_{j t}
$$

where $\xi_{j t}$ captures all unobserved product characteristics and a deviation from this mean utility $\mu_{i j t}=p_{j t} \sigma v_{i}$. The indirect utility is then given by:

$$
V_{i j t}=\delta_{j t}+\mu_{i j t}+\varepsilon_{i j t}
$$

The consumer can decide not to choose one of the considered products. Thus, we introduce an outside option that allows for substitution between the considered products and a substitute. The utility of the outside good is normalised to zero. The indirect utility of choosing the outside good is $V_{i 0 t}=\varepsilon_{i 0 t}$.

Assuming that $\varepsilon_{i j t}$ is independently and identically distributed like an extreme value type I distribution, we are able to write the market share of product $j$ at period $t$ in the following way (Nevo, 2001):

$$
s_{j t}=\int_{A_{j t}}\left(\frac{\exp \left(\delta_{j t}+\mu_{i j t}\right)}{1+\sum_{k=1}^{J_{j}} \exp \left(\delta_{k t}+\mu_{i k t}\right)}\right) d P_{v}(v)
$$

where $A_{j t}$ is the set of consumers who have the highest utility for product $j$ at period $t$, a consumer being defined by the vector $\left(v_{i}, \varepsilon_{i 0 t}, \ldots, \varepsilon_{i J t}\right)$.

The random coefficients logit model generates a flexible pattern of substitutions between products, driven by the different consumer price disutilities $\alpha_{i}$. Thus, the own- and 
cross-price elasticities of the market share $s_{j t}$ can be written as:

$$
\frac{\partial s_{i j t}}{\partial p_{k t}} \frac{p_{k t}}{s_{i j t}}=\left\{\begin{array}{cl}
-\frac{p_{j t}}{s_{j t}} \int \alpha_{i} s_{i j t}\left(1-s_{i j t}\right) \phi\left(v_{i}\right) d v_{i} & \text { if } j=k \\
\frac{p_{k t}}{s_{j t}} \int \alpha_{i} s_{i j t} s_{i k t} \phi\left(v_{i}\right) d v_{i} & \text { otherwise. }
\end{array}\right.
$$

\subsection{Identification and estimation method}

For each market, an independent demand model is estimated using individual data. We randomly choose 100,000 observations among the 4,450,818 we have in the database of dairy desserts and also 100,000 observations among the 596,850 we have in the database of fluid milk. ${ }^{17}$ We use the simulated maximum likelihood method, as in Revelt and Train (1998). ${ }^{18}$

This method relies on the assumption that in the dairy desserts market (the fluid milk market, respectively), all product characteristics $X_{j t}=\left(p_{j t}, C_{j}, D_{j}, l_{j}\right)\left(X_{j t}=\left(p_{j t}, S_{j}, W_{j}\right)\right.$, resp. $)$ are independent of the error term $\varepsilon_{i j t}$. However, assuming that $\varepsilon_{i j t}=\xi_{j t}+e_{i j t}$, where $\xi_{j t}$ is a product-specific error term varying across periods and $e_{i j t}$ is an individual specific error term, the independence assumption cannot be upheld if unobserved factors included in $\xi_{j t}$ (and hence in $\varepsilon_{i j t}$ ) such as promotions, displays, or advertising are correlated with observed characteristics $X_{j t}$. For instance, we do not know how much each firm invests in advertising for its brands. This effect is thus included in the error term because advertising might play a role in households' choices of products. Because advertising represents an appreciable share of production costs, it is clearly correlated with prices. To address the problem that the omitted product characteristics might be correlated with prices, we use a two-stage residual

\footnotetext{
17 Due to computing constraints, we were not able to estimate the demand model using the whole sample. The sample used is representative of the whole sample over products and periods.

18 Models were estimated using 100 draws for the parametric distribution that represents the unobserved consumer characteristics.
} 
inclusion method, as in Terza, Basu and Rathouz (2008) and Petrin and Train (2010). The first stage consists of regressing prices on instrumental variables (input prices) and the exogenous variables of the demand equation brand and retailer fixed effects. This can be written as:

$$
p_{j t}=W_{j t} \gamma+\delta_{b(j)}+\delta_{r(j)}+\tau X_{j}+\eta_{j t}
$$

where $W_{j t}$ is a vector of input price variables, $\gamma$ is the vector of associated parameters, $\delta_{b(j)}$ and $\delta_{r(j)}$ are brand and retailer fixed effects, $\tau$ is the vector of coefficients associated with the exogenous variables of the demand model, and $\eta_{j t}$ is an error term that captures the remaining unobserved variations in prices. The estimated error term $\hat{\eta}_{j t}$ of the price equation includes some omitted variables such as variations in advertising and promotions or in-shelf displays that are not captured by the other exogenous variables of the demand equation and by the cost shifters. Introducing this term into the mean utility of consumers $\delta_{j t}$ allows for the capturing of unobserved product characteristics that may vary across time. Thanks to this second stage, prices are now uncorrelated with the new product-specific error term varying across periods $\zeta_{j t}=\xi_{j t}+\varepsilon_{j h t}-\pi \hat{\eta}_{j t}$.

We then write:

$$
\delta_{j t}=\beta_{b(j)}+\beta_{r(j)}+\alpha p_{j t}+\beta X_{j}+\zeta_{j t}+\pi \hat{\eta}_{j t}
$$

where $\pi$ is the estimated parameter associated with the estimated error term of the first stage.

In practice, we use the price indices for the main inputs used in the production of desserts or milk because it is unlikely that the input prices are correlated with unobserved determinants of demand for these products. In the case of dairy desserts, we use the quarterly price of raw milk and the quarterly price indices of wages, gasoline, aluminium, glass, and metal. In the 
case of fluid milk, we use only the quarterly price of raw milk and the quarterly price indices of wages, gasoline, and cardboard. ${ }^{19}$ These variables are interacted with PL/NB dummies because we expect that the manufacturers obtain different prices from suppliers of raw materials according to what they produce. We also expect that certain characteristics of the inputs depend on the PL/NB characteristics of products.

\subsection{Supply models: Vertical relationships between processors and retailers, cost specification, and selection of the best model}

Contracts between manufacturers and retailers, the degree of competition, and market power within the industry under investigation can modify the price transmission of cost shocks (Bettendorf and Verboven, 2000; Bonnet et al. 2013). In food chains, both upstream and downstream industries are highly concentrated. In such a context of a chain of oligopolies, linear contracts are not efficient because, due to double marginalisation, the profit of the chain is not maximised. More complex contracts allow the whole industry to maximise the industry profit. In this paper, we consider linear pricing and a set of two-part tariff contracts in which the processors have all of the bargaining power. The general framework of the vertical relationships is described by the following game:

- Stage 1: manufacturers simultaneously propose "take-it-or-leave-it" contracts to retailers. In the case of linear pricing, the contract simply consists of a set of wholesale prices because the manufacturers produce a set of different brands. In this case, manufacturers compete à la Bertrand-Nash as they compete on prices. With a two-part tariff, the contract includes a set of wholesale prices and fixed fees. Finally, in the case of resale price maintenance (RPM), the contract is composed of a set of wholesale prices, fixed fees, and consumer prices.

- $\quad$ Stage 2: retailers simultaneously accept or reject the offers, which are public

\footnotetext{
${ }^{19}$ These indices are taken from the French National Institute for Statistics and Economic Studies.
} 
information. If a retailer rejects one offer, it earns some profit from an "outside option”. We consider two possibilities. In the first case, the outside option is exogenously set to a positive fixed value. In the second case, the outside option is determined endogenously and its amount is equal to the profit that a retailer gets from selling its own PLs.

- $\quad$ Stage 3: retailers set consumer prices and thus compete à la Bertrand-Nash.

Depending on the assumptions regarding contracts and the outside option of retailers, we specify seven different cases: linear pricing, and six cases of non-linear contracts. The six cases of non-linear pricing derive from the combination of three types of contracts proposed by manufacturers with the two possibilities for the outside option of retailers. The three non-linear contracts correspond to a two-part tariff without RPM and two possibilities for a two-part tariff with RPM. With RPM, we consider the two polar cases for price-cost margins: zero wholesale margins for $\operatorname{NBs}\left(w_{j}-\mu_{j}=0\right)$ or, alternatively, zero retail margins for NBs $\left(p_{j}-w_{j}-c_{j}=0\right)$.

Thanks to the first-order conditions derived from the supply models and demand estimates, we are then able to compute estimated price-cost margins of manufacturers and retailers for each product and estimated total marginal costs (for a detailed presentation of the different cases, refer to Bonnet and Dubois (2010) and Bonnet and Réquillart (2013).

Once the demand model is estimated, for each model of vertical interactions between manufacturers and retailers, the price-cost margins can be computed. As prices are known, we obtain estimated marginal costs $C_{j t}^{h}=p_{j t}-\Gamma_{j t}^{h}-\gamma_{j t}^{h}$ for each product $j$ at period $t$ for any supply model $h$, where $\Gamma_{j t}^{h}=w_{j t}^{h}-\mu_{j t}^{h}$ is the manufacturer's margin and $\gamma_{j t}^{h}=p_{j t}^{h}-$ $w_{j t}^{h}-c_{j t}^{h}$ is the retailer's margin.

We specify the following model for the estimated marginal costs in the case of dairy 
desserts:

$$
C_{j t}^{h}=\sum_{k=1}^{K} \lambda_{k}^{h} W_{j t}^{k}+w_{b(j)}^{h}+w_{r(j)}^{h}+\eta_{j t}^{h}
$$

and in the case of fluid milk:

$$
C_{j t}^{h}=\sum_{k=1}^{K} \lambda_{k}^{h} W_{j t}^{k}+w_{r(j)}^{h}+\eta_{j t}^{h}
$$

where $W_{j t}$ is a vector of inputs, $w_{b(j)}^{h}$ represents the brand fixed effects for model $h$, and $w_{r(j)}^{h}$ is the retailer fixed effect for model $h$. We suppose that $E\left(\eta_{j t}^{h} \mid W_{j t}^{\prime}\right)=0$ to consistently identify and estimate $\lambda_{k}^{h}, w_{b(j)}^{h}$ and $w_{r(j)}^{h} \cdot{ }^{20}$ To be consistent with the economic theory, as in Gasmi, Laffont and Vuong (1992), we impose the positivity of parameters $\lambda_{k}^{h}$ and use a non-linear least squares method to estimate them. We use this cost function specification to test any pair of supply models $C_{j t}^{h}$ and $C_{j t}^{h^{\prime}}$ and we infer which model is statistically the best using a non-nested Rivers and Vuong (2002) test. ${ }^{21}$

\subsection{Simulations}

Using the estimated marginal costs from the preferred model of contracts in the vertical chain as well as the other estimated structural parameters from the demand estimation, we can simulate the impact on retail prices of a change in the raw milk price. We denote $C_{t}=\left(C_{1 t}, \ldots, C_{j t}, \ldots, C_{J t}\right)$ the vector of marginal costs for all products present at period $t$. To model the impact of a change in the raw milk price, we have to solve the following program:

$$
\min _{\left\{p_{j t}^{*}\right\}_{j=1, \ldots, J}}\left\|p_{t}^{*}-\Gamma_{t}\left(p_{t}^{*}\right)-\gamma_{t}\left(p_{t}^{*}\right)-\tilde{C}_{t}\right\|
$$

where $\|$.$\| is the Euclidean norm in \mathbb{R}^{J}, \gamma_{t}$ and $\Gamma_{t}$ correspond respectively to the retail and

\footnotetext{
${ }^{20}{ }^{20}$ In the case of fluid milk, we do not introduce brand fixed effects as we do in the dairy desserts case. This is explained by the fact that heterogenous costs exist between brands of desserts, whereas fluid milk is quite a homogenous product and its marginal cost does not differ across brands.

${ }^{21}$ In the following, we refer to this model as the preferred model of contracts.
} 
wholesale margins for the best supply model, and $\tilde{C}_{t}$ is the vector of marginal cost estimated using the new raw milk price. If $\lambda_{R}^{h}$ is the impact of the raw milk price on total marginal cost of the best supply model $h$, then we have $\tilde{C}_{t}=C_{t}+\theta \lambda_{R}^{h}$ where $\theta$ is the magnitude of the shock on the raw milk price.

\section{Results for Demand, Vertical Relationships, and Cost Pass-Through}

\subsection{Demand results}

Table 3 provides the results for the demand estimates in both markets. First of all, the coefficient of the error term in the price equations is positive and significant for each

sector. ${ }^{22}$ It means that the unobserved part explaining prices is positively correlated with the choice of the alternative in each market and justifies the need to control for the endogeneity problem (we provide results for the price equations in Table 11 in the Appendix). The instrumental variables used are not weak and significantly affect prices (cf F-test of input price indices in each market). Moreover, correlation between instruments is not high.

\section{INSERT TABLE 3}

In order to obtain better demand models, we introduced some product heterogeneity into the price sensitivity. Heterogeneity taken into account is related to the choice of NB or PL products. On average, the price has a significant and negative impact on utility. In both markets, consumers are more sensitive to the price variations of PLs than to NBs, suggesting that consumers might have more loyalty with respect to NBs than to PLs. The case of the

\footnotetext{
${ }^{22}$ In the case of fluid milk, we assume that the error term $\hat{\eta}_{j t}$ can be different depending on whether it is an NB or a PL product. This allows taking into account some unobserved information that affects PLs and NBs in different ways. For example, PLs are frequently put in a more favourable positions on retailers' shelves than NBs.
} 
fluid milk market is interesting. NBs' market shares are relatively low and the price difference between NBs and PLs is small. In other words, NBs cannot maintain significant market shares and high prices. This suggests relatively low product differentiation between both types of products. In this context, we interpret the difference in price sensitivity of consumers as follows: NBs' actual consumers are the proportion of consumers who are brand 'addicts' and they do not switch easily to PLs. On the other hand, consumers of PLs can switch to the NBs if the price of PLs increases (Gabrielsen and Sorgard (2007) developed a model with such behaviours). It is also interesting to note that regarding retailers' fixed effects, we get similar results in both markets as fixed effects reveal consumers' preferences for a given retailer as compared to a reference one, which is the aggregate of discounters. Our results mean that preferences for retail chains are not product specific but are linked to general characteristics of the chain such as the services offered or the number of cashiers.

Let us now comment in more detail on the results for dairy desserts. Consumers prefer 'other dairy desserts' to yoghurts (as the mean coefficient for 'other dairy desserts' is positive, cf. Table 3) and yoghurts to cottage cheese (as the mean coefficient for cottage cheese is negative). They also prefer regular products to diet products. We also introduced brand fixed effects that reveal the mean preference of consumers for products. ${ }^{23}$ Using the structural demand estimates, we compute own- and cross-price elasticities for each differentiated product. The own-price elasticities of demand for a brand vary between -8.27 and -2.97 , with an average value of -4.77 (Table 4). Price elasticities are heterogeneous and in general rather high (in absolute terms). This could be explained by the number of alternatives that are considered in this market. Demand for regular products is more elastic than demand for diet

\footnotetext{
${ }^{23}$ The coefficients of brand fixed effects cannot be compared directly as brands differ by characteristics that are taken into account inthe preferences for diet (as compared to regular) products or for the product category. For example, to compare the preferences among NB yoghurts, the brand fixed effect of diet brands has to be corrected by the coefficient attached to the diet taste.
} 
products. Indeed, the average own-price elasticity of demand for regular brands of desserts is -5.07 while it is -3.92 for diet brands. If we compare the demand for yoghurts, cottage cheeses, and other dairy desserts, we observe that the demand for other dairy desserts is more elastic than the demand for cottage cheeses and both demands are more elastic than the demand for yoghurts, with average own-price elasticities of demand of $-6.33,-4.90$, and -4.04 , respectively.

\section{INSERT TABLE 4}

In the fluid milk market, households have a significant preference for semi-skimmed milk since the mean coefficients of both skimmed and whole milk are negative. The brand fixed effects reveal that PLs give the highest utility to households with respect to the other products. This might be explained by the fact that in this market consumers are more sensitive to the level of prices than to the brand they consume. One reason could be that fluid milk is a quite homogeneous product. The own-price elasticities of demand for a brand vary between -6.56 and -1.79, with an average value of -3.01 (Table 4). On average, elasticities of demand for the different product categories are similar, as the own-price elasticities of whole, semi-skimmed, and skimmed milk products are 3.36, -3.12 , and -2.80 , respectively. To interpret these elasticities, it is important to have in mind that these are product elasticities. ${ }^{24}$ The literature frequently reports lower price elasticities, but they are generally evaluated for a more aggregated market. For example, Jonas and Roosen (2008) reported own-price elasticities for conventional milk around unity in the German milk market. When considering a larger number of alternatives, reported results are in line with ours. Thus, Lopez and Lopez (2009) found own-price elasticities ranging from -1.9 to -2.4 for different

\footnotetext{
${ }^{24}$ In this analysis, a product is the combination of a brand and the location of purchase. A product is in competition with a large number of alternatives, which explains the very elastic demand for each product.
} 
brands, and Kinoshita et al. (2001) found elasticities ranging from -0.2 to -6.1 depending on the brand and the store, with an average own-price elasticity of -2.8.

\subsection{Preferred model, price-cost margins, and cost estimates}

Using the demand estimates, we compute the price-cost margins and the marginal costs for each supply model. On the basis of the Rivers and Vuong test (2002), the best supply model for the dairy desserts market is model ' 3 ' whereas it is model ' 6 ' for the fluid milk market (Table 15 in the Appendix). These results mean that manufacturers and retailers use two-part tariff contracts with RPM and the distribution margin is equal to zero (meaning that the consumer selling price is equal to the sum of the wholesale price and marginal costs) in both markets. As in the French soft drink market (Bonnet and Réquillart, 2013), the French bottled water sector (Bonnet and Dubois, 2010), or the German coffee market (Bonnet et al., 2013), we find that manufacturers and retailers use two part-tariff contracts with RPM. Then, the share of profits within the chain depends on the fixed fees, which are not observed. The PLs, however, play a strategic role in the fluid milk market, which is not the case for the dairy desserts market. The large market share of PLs and the strong substitutability between PLs and NBs in the fluid milk market could explain this result. In addition, there are many small firms that produce fluid milk (in 2010, there were 134 firms in this industry in France). It is therefore easy for retailers to find alternative producers for their procurement to replace NBs if needed. Then, PLs can play a strategic role.

Marginal costs, which include processing and retailing costs, are product- and time-specific. In the dairy desserts market, marginal costs of yoghurts, cottage cheese, and other dairy desserts amount to $€ 1.52$, €1.99, and $€ 2.78$ per kilogram respectively, on average (Table 12 in the Appendix). For yoghurts, there are no cost differences between regular and diet products. For cottage cheese, a diet PL is less costly to produce than a regular PL. Finally, for other dairy desserts, only regular products are produced. For each category, the marginal 
cost of the PL product is significantly lower than that of NBs. In the fluid milk market, marginal costs of PLs tend to be slightly higher than those of NBs (Table 13 in the Appendix). ${ }^{25}$ This result suggests that PLs and NBs are not different and in such a context NB producers are more efficient than PL producers (an assumption that is frequently made in the literature, e.g., Berges-Sennou and Bouamra (2012). Among retailers, marginal costs in retailer 7 are the lowest ones. This is consistent with the strategy of retailer 7 , which offers only a few services to consumers.

The raw milk price plays a significant role in the formation of marginal costs of all products (Table 14 in the Appendix). For yoghurts, the coefficient for regular products is 1.16 but not significantly different to 1 , which is the expected value, as producing one kilogram of plain yoghurt requires one litre of milk (Meyer and Duteurtre, 1998). The coefficient for the 'diet' yoghurt is lower than 1 , which is also expected, as to produce low-fat yoghurt requires less milk equivalent since part of the fat is extracted. For cottage cheese, the coefficient is larger than 1 as expected, since producing one kilogram of cottage cheese requires more than one litre of milk. We find, however, a relatively low coefficient since the technical coefficient of production is larger than 2. Finally, for dairy desserts, it is much more complex to draw a parallel with the technology as these products are very diverse. In any case, milk is not the only ingredient and it thus makes sense to find a coefficient that is lower than 1 . For fluid milk, the coefficient for whole milk is very close to $1(0.94)$, which is in line with the technology, as production of one litre of fluid milk requires one litre of raw milk. For non-whole milk (we did not differentiate in the cost function between semi-skimmed and skimmed milk), the coefficient is lower than 1, which is also in line with the technology. It is, however, a little too low, as to produce a litre of skimmed milk requires 0.7 litre milk

\footnotetext{
${ }^{25}$ This excludes the marginal cost of brands 10 and 11, which are underestimated, almost certainly because these products are priced at rather low prices for NBs. Thus, brands 10 and 11 are an aggregate of NBs with very low market share. Most are produced by relatively small firms. In our analysis, we choose to aggregate these brands because we do not have sufficient information to consider them separately. It is likely that these firms do not have the same market power as compared to the main NBs. By considering them as an aggregate, we almost certainly over-estimate their market power and thus the margins. This is why we find very low costs.
} 
equivalent (Meyer and Duteurtre, 1998). ${ }^{26}$

\subsection{Simulations}

To evaluate how retail prices change in response to a change in the raw milk price in those markets, we test the impact of a $10 \%$ decrease in the raw milk price. ${ }^{27}$ Using the estimated marginal cost and cost specification, we are able to assess the impact of a change in the raw milk price on the marginal cost of the different products. Then, we recover the new equilibrium prices using (3).

\subsubsection{Results in the case of dairy desserts}

On average, the $10 \%$ decrease in the milk price causes a $€ 2.60$ cents per kilogram (1.91\%), $€ 3.66$ cents per kilogram (1.99\%), and €1.35 cents per kilogram (0.55\%) reduction in the total marginal cost of yoghurts, cottage cheeses, and other dairy desserts, respectively. The $10 \%$ decrease in the milk price has a lower impact on the marginal costs of diet products, which are low fat and thus contain less milk equivalent, than on marginal costs of regular products. On average, marginal costs of regular products decrease by $€ 2.86$ cents per kilogram (1.69\%), whereas it is $€ 1.90$ cents per kilogram (1.47\%) for diet products.

\section{INSERT TABLE 5}

As a consequence of the reduction in marginal costs, consumer prices decrease by $1.1 \%$,

\footnotetext{
${ }^{26}$ In the cost model, we did not differentiate between semi-skimmed and skimmed milk, as this led to unrealistic results. When differentiating the two products, we obtained a marginal cost of production for semi-skimmed milk that was muchlower than that of skimmed milk. This result is not plausible as the milk equivalent coefficient for producing semi-skimmed milk has been higher than that of skimmed milk. The difficulty comes from estimating the price-cost margins. Because we obtained identical price-cost margins and because, since 2008, the price of skimmed milk has been higher than that of semi-skimmed milk, we thus obtained a higher cost for skimmed milk. This explains why we chose not to differentiate between the two products in the cost equation, even if this led us to under-estimate the marginal cost of production of semi-skimmed milk.

${ }^{27}$ We obtain the same results simulating a $10 \%$ increase in the raw milk price.
} 
$1.3 \%$, and $0.3 \%$ for yoghurts, cottage cheeses, and other dairy desserts, respectively. The percentage variation of the price of dairy desserts is very small as these products have a rather low level of milk content. The pass-through, which is measured by the ratio of the difference in retail prices to the difference in marginal costs, is lower than 1 for all brands. For yoghurts, the pass-through has an average value of 0.83 . Therefore, if the marginal cost decreases by $€ 1$ cent/kilogram, the retail price decreases by an average of $€ 0.83$ cents/kilogram. The industry thus undershifts the cost change.

The pass-through is brand specific and varies from 0.55 to 0.99 . For the NBs, it seems to be unrelated either to the firm or to the kind of product, even if the pass-through rates of other dairy desserts are the lowest ones ( 0.64 on average). The pass-through for PLs is larger than that of NBs. It is almost 1, meaning that retailers pass on to consumers most of the cost changes, which is not the case for manufacturers. A consequence is that the percentage reduction in PL prices is larger than that of NB prices because PLs are cheaper than NBs and because retailers transmit cost changes to consumers to a larger extent. Because the contract between manufacturers and retailers includes RPM, manufacturers decide the final prices for their products. They choose a pricing policy for the entire set of products, thereby internalising the substitution among their own set of products.

\subsubsection{Results in the case of fluid milk}

On average, the $10 \%$ decrease in the milk price causes a $€ 1.77$ cents/litre reduction (approximately 4.1\%) in the total marginal cost of fluid milk in general. The impact on marginal costs is lower for semi-skimmed and skimmed milk (€1.31 cents/litre, or about 3.7\%) than for whole milk (€2.65 cents/litre, or about 5.0\%). As discussed above, the coefficients of the milk price in the cost equation were lower for semi-skimmed and skimmed milk than for whole milk. In response to the marginal cost change, consumer prices decrease on average by $1.81 \%, 1.92 \%$, and $3.36 \%$ for skimmed, semi-skimmed, and whole 
milk, respectively. For semi-skimmed milk, the pass-through has an average value of 1.11. Therefore, if the marginal cost decreases by $€ 1$ cent/kilogram, the retail price decreases by an average of $€ 1.11$ cents/kilogram. The industry thus overshifts the cost decrease.

The pass-through varies from 0.97 to 1.33 . Among the NBs, the greatest rates of pass-through are obtained for whole milk. The pass-through rate for PLs is smaller than that of NBs and also close to 1 in this market. Unlike the dairy desserts case, the percentage price reduction for the PLs is nearly the same as it is for the NBs, even if PLs are cheaper than NBs. This is because the cost pass-through rate for PLs is lower than that for NBs.

\subsubsection{Synthesis of results}

To sum up the results of cost pass-through rates across both markets, we regress cost pass-through estimates on market characteristics (Table 6). We defined two models. Model 1 assesses the differences between markets, producers, and retailers. Markets are taken into account through manufacturers. ${ }^{28}$ The results suggest that there exists more heterogeneity across manufacturers or markets than across retailers.

INSERT TABLE 6

As discussed in the previous section, the pass-through rates for NBs in the fluid milk market are higher than the rate in the dairy desserts market. This explains why the fixed effects associated with manufacturers 4 to 7 are much lower than those associated with manufacturers 1 and 2. Little heterogeneity exists between retailers even if retailer 7, the aggregated hard discounter, is the one that transmits lower cost shocks on average. Retailers transmit cost shocks onto PL prices in a similar way in both markets since the coefficient of the variable 'Private labels (fluid milk)' is not significant. Table 6 also presents the results of

\footnotetext{
${ }^{28}$ We cannot identify the market effect from the manufacturer effect as there is no manufacturer present in both markets. Thus, manufacturers 1 to 3 are present in the fluid milk market whereas manufacturers 4 to 7 are present in the dairy desserts market.
} 
model 2, in which we regress the rate of pass-through on the manufacturers' and retailers' market shares, on the share of PLs, and on the market dummy. As anticipated, we found that the pass-through rate is higher for fluid milk than for dairy desserts. This taken into account, we found that manufacturers with large market shares transmit less than smaller manufacturers. A similar result is found for retailers too. We also found that the share of PLs in the market has an impact on pass-through. The impact on the pass-through for NBs is negative. The higher the PL share is in a market, the lower the pass-through for NBs will be. On the contrary, the impact on the pass-through for PLs is positive. The higher the share of PLs in a market, the higher the pass-through for PLs will be. It should be noted that if there is a market effect, it is difficult to know if this is related to some characteristics of the market, or to the contracts that are in place. We have shown that the contracts used in these two markets are different and, as shown by Bonnet et al. (2013), the type of contract has an impact on price transmission. ${ }^{29}$ Pass-through might also be related to the value of the elasticities. It is worth mentioning that for NBs, elasticities are much higher (in absolute terms) in the dairy desserts market than in the fluid milk market. With a lower elasticity, a price change has less impact on demand, which might explain a higher pass-through.

\section{Conclusion}

This paper provides a general methodology for evaluating price transmission in vertically related markets. This method allows us to assess the effects of changes in input prices on consumer prices by considering the pricing strategies of manufacturers and retailers in the food supply chain. We analyse the impact on two dairy markets of a change in the raw milk price. Using recent developments in the empirical industrial organisation literature, we have estimated a flexible demand model, a random coefficients logit model, and several models

\footnotetext{
${ }^{29}$ We evaluated the pass-through in the fluid milk market assuming the contract between manufacturers and retailers is characterized by RPM without a strategic role for PLs. We obtain very different results, in particular for skimmed and semi-skimmed NBs. For these products, the pass-through is lower than 1 (about 0.8). This is another example of the impact of the type of contracts on price transmission.
} 
for the vertical relationships within the industry. We have shown that the most likely supply model is the model in which the manufacturers and retailers use two-part tariff contracts with RPM. In the dairy desserts market, PLs play no role in manufacturer/retailer relationships, whereas in the fluid milk market, they do play a role. In the latter case, PLs have a rather large market share, and retailers can procure fluid milk from several small producers. Moreover, products are not strongly differentiated in this market. Then, retailers can use PLs as a strategic tool in their negotiations with brand manufacturers. On the contrary, in the dairy desserts market, manufacturers still possess significant market power due to the strength of their brands. This result is consistent with anecdotal evidence with respect to this specific industry because the firms use investments in advertising to build strong reputations. Using the model that best fits the data, we have simulated the impact on consumer prices of a decrease in the raw milk price, taking into consideration strategic choices of the agents. We have shown that the pass-through for NBs is greater than 1 in the fluid milk market whereas it is lower than 1 on the dairy dessert market. Depending on the market, therefore, firms will overshift or undershift cost changes. It should be noted that in both markets, we found that PLs transmit the cost change (the pass-through is very close to 1 for all PLs, whatever the market considered). Whereas undershifting a cost change is the rule in a perfect competition framework (Stern, 1987), under conditions of imperfect competition, undershifting or overshifting is possible (Stern, 1987; Delipalla and Keen, 1992; Anderson , de Palma and Kreider, 2001). The literature also shows that conditions for overshifting of a cost change are related to conditions related to the elasticity of the slope of the demand curves. Moreover, as shown by Bonnet et al. (2013), the type of contracts linking manufacturers and retailers might also play a role.

According to these results, any analysis of the impact of food price policies requires that the strategic pricing of firms be addressed. We cannot, however, easily extrapolate our results to other industries. Neither the type of contracts used by a specific industry nor the qualitative 
results (e.g., the over-shifting of cost changes) can be generalised. First, the structure of the upstream industry plays a role in the choice of contracts between manufacturers and retailers. In the specific case of food markets, the structure of the upstream industry varies significantly from a low level of concentration (e.g., the meat industry or the wine industry) to a high level of concentration (e.g., the processed cheese industry or the bottled water industry). Second, the strategic response depends on the curvature of the demand function, which is also market-specific. Finally, the type of contracts also affects cost pass-through. As a consequence, the empirical analysis of price transmission in a given industry requires that the vertical relationships of this particular industry and the substitution patterns of consumers be evaluated first.

In our analysis, because we have assumed that consumers react identically to a price decrease or to a price increase, cost decreases or cost increases are transmitted in the same manner. The possibility of asymmetric price transmission is abundant in the literature that uses time-series analysis. The general finding is that positive cost shocks are transmitted at a faster rate than negative cost shocks (for a recent survey, refer to Frey and Manera, 2007). Our study focuses more specifically on what occurs at the equilibrium. The model that we employ is static, and we focus on the change in equilibrium rather than on the speed or the path of adjustment. In that case, the results of an asymmetric price response (from time-series analysis) might be less clear. For example, in his study, Peltzman (2000, pp. 486-487) stated that: "The important result is that there is no evidence of any permanent effect of asymmetries on the long-run trend of output prices: none of the relevant coefficients differ from zero. These results imply that the asymmetries do ultimately disappear but that it takes longer than five or eight months for this to happen."

A second limitation relies on the relative homogeneity in the strategic behaviour of the different retailers. In reality, it appears that some heterogeneity exists in the way in which retailers adjust their prices. This observation stems from the fact that in the models 
constructed, retailers have similar vertical arrangements with manufacturers, while this might not always be the case in practice.

A third difficulty is to assess the role of small NBs in markets. The way to consider these brands is to aggregate them into a single NB. This is required as we do not have information on the manufacturers of those brands. By doing so, however, we likely over-estimate their market power, leading to under-estimation of their production costs. Taking into better account the role of these small NB producers is another challenge for this kind of approach. 


\section{References}

AFSSA (2009). Etude individuelle des consommations alimentaires 2 (INCA2) 2006-2007. 228p. http://www.anses.fr/sites/default/_les/documents/paser-ra-inca2.pdf (accessed 2014, june 6).

Allais, O., Bertail, P. and Nichele, V. (2010). The effects of a fat tax on French households' purchases: a nutritional approach. American Journal of Agricultural Economics 92(1):228-245.

Anderson, S. P., de Palma, A. and Kreider, B. (2001). Tax incidence in differentiated product oligopoly. Journal of Public Economics 81 (2): 173-192.

Berges-Sennou, F. and Bouamra, Z. (2012). Is producing a private label counterproductive for a branded manufacturer? European Review of Agricultural Economics 39(2): 213-239.

Berry, S., Levinsohn, J. and Pakes, A. (1995). Automobile prices in market equilibrium. Econometrica 63: 841-890.

Berto Villas-Boas, S. (2007). Vertical relationships between manufacturers and retailers: Inference with limited data. Review of Economic Studies 74: 625-652.

Bettendorf, L. and Verboven, F. (2000). Incomplete transmission of coffee bean prices: evidence from the Netherlands. European Review of Agricultural Economics 27(1): 1-16.

Bonnet, C. and Dubois, P. (2010. Inference on vertical contracts between manufacturers and retailers allowing for non-linear pricing and resale price maintenance. Rand Journal of Economics 41(1): 139-164.

Bonnet, C., Dubois, P., Klapper, D. and Villas-Boas, S. (2013). Empirical evidence on the role of nonlinear wholesale pricing and vertical restraints on cost pass-through. Review of Economics and Statistics 95(2): 500-515.

Bonnet, C. and, Réquillart, V. (2013). Impact of cost shocks on consumer prices in vertically related markets: The case of the French soft drink market. American Journal of Agricultural Economics 95(5): 1088-1108.

Bouamra-Mechemache Z., Jongeneel R. and Réquillart V. (2008). Impact of a gradual increase in milk quotas on the EU dairy sector. European Review of Agricultural Economics 35(4): 461-491.

Bouamra, Z., Réquillart, V., Soregaroli, C. and Trevisiol, A. (2008). Demand for dairy products in the EU. Food Policy 33: 644-656.

Bukeviciute, L., Dierx, A. and Ilzkovit, F. (2009). The functioning of the food supply chain and its effect on food prices in the European Union. European Economy, Occasional papers 47.

Delipalla, S. and Keen, M. (1992). The comparison between ad valorem and specific taxation under imperfect competition. Journal of Public Economics 49(3): 351-367. 
Food Drink-Europe (2014). Data and trends of the European food and drink industry 2013-2104. Technical report, Food Drink Europe, 28p.

Frey, G. and Manera, M. (2007). Econometric models of asymmetric price transmission. Journal of Economics Surveys 21(2): 349-415.

Gabrielsen, T. S., Sorgard, L. (2007. Private labels, price rivalry, and public policy. European Economic Review 51(2): 403-424.

Gasmi, F., Laffont, J. and Vuong, Q. (1992). Econometric analysis of collusive behavior in a soft-drink market. Journal of Economics \& Management Strategy 12(1): 277-311.

Hassouneh, I., Holst, C., Serra, T., Cramon-Taubadel (von), S. and Gil, J. (2013). Overview of price transmission and reasons of different adjustments in different EU member states. Technical report, TRANSFOP projet (KBBE-265601-4).

Hellerstein, R. (2008). Who bears the cost of a change in the exchange rate? Pass-through accounting for the case of beer. Journal of International Economics 76 (1): 14-32.

Jonas, A. and Roosen, J. (2008). Demand for milk labels in Germany: organic milk, conventional brands, and retail labels. Agribusiness 24(2): 192-206.

Kim, D. and Cotterill, R. W. (2008). Cost pass-through in differentiated product market: the case of US processed cheese. Journal of Industrial Economics LV(1): 32-48.

Kinoshita, J., Suzuki, N., Kawamura, T., Watanabe, Y. and Kaiser, H. M. (2001). Estimating own and cross brand price elasticities, and price-cost margin ratios using store-level daily scanner data. Agribusiness 17 (4): 515-525.

Lloyd, T., McCorriston, S., Morgan, W. and Zgovu, E. (2013). European retail food price ination. EuroChoices 12: 37-44.

Lopez, E. and Lopez, R. A. (2009). Demand for differentiated milk products: implications for price competition. Agribusiness 25(4): 453-465.

Loy, J.P., Holm, T., Steinhagen, C. and Glauben, T. (2014). Cost pass-through in differentiated product markets: a disaggregated study for milk and butter. European Review of Agricultural Economics, doi:10.1093/erae/jbu031.

McCorriston, S. (2013). Competition in the food chain. TRANSFOP, WP nº11.

McFadden, D. and Train, K. (2000). Mixed MNL models for discrete response. Journal of Applied Econometrics 15(5): 447-470.

Meyer, C. and Duteurtre, G. (1998). Equivalents lait et rendements en produits laitiers: modes de calcul et utilisation. Revue Elevage Méditérannéen Médecine Vétérinaire Pays Tropicaux 51(3) :, 247-257.

Nakamura, E. and Zerom, D. (2010). Accounting for incomplete pass-through. Review of Economic Studies 77(3): 1192-1230.

Peltzman, S. (2000). Prices rise faster than they fall. Journal of Political Economy 108(3):466-502. 
Petrin, A. and Train, K. (2010). A control function approach to endogeneity in consumer choice models. Journal of Marketing Research 47(1): 3-13.

Revelt, D. and Train, K. (1998). Mixed logit with repeated choices: households' choices of appliance efficiency level. Review of Economics \& Statistics 80(4): 647-657.

Rivers, D. and Vuong, Q. (2002). Model selection tests for nonlinear dynamic models. The Econometrics Journal 5(1): 1-39.

Steiner, R. (1993). The inverse association between the margins of manufacturers and retailers. Review of Industrial Organization 8: 717-740.

Stern, N. (1987). The effects of taxation, price control and government contracts in oligopoly and monopolistic competition. Journal of Public Economics 32(2): 133-158.

Terza, J., Basu, A. and Rathouz, P. (2008). Two-stage residual inclusion estimation addressing endogeneity in health econometric modeling. Journal of Health Economics 27(3): 531-543. 


\section{Figures}

Figure 1: Raw milk price in France 1990 - 2011

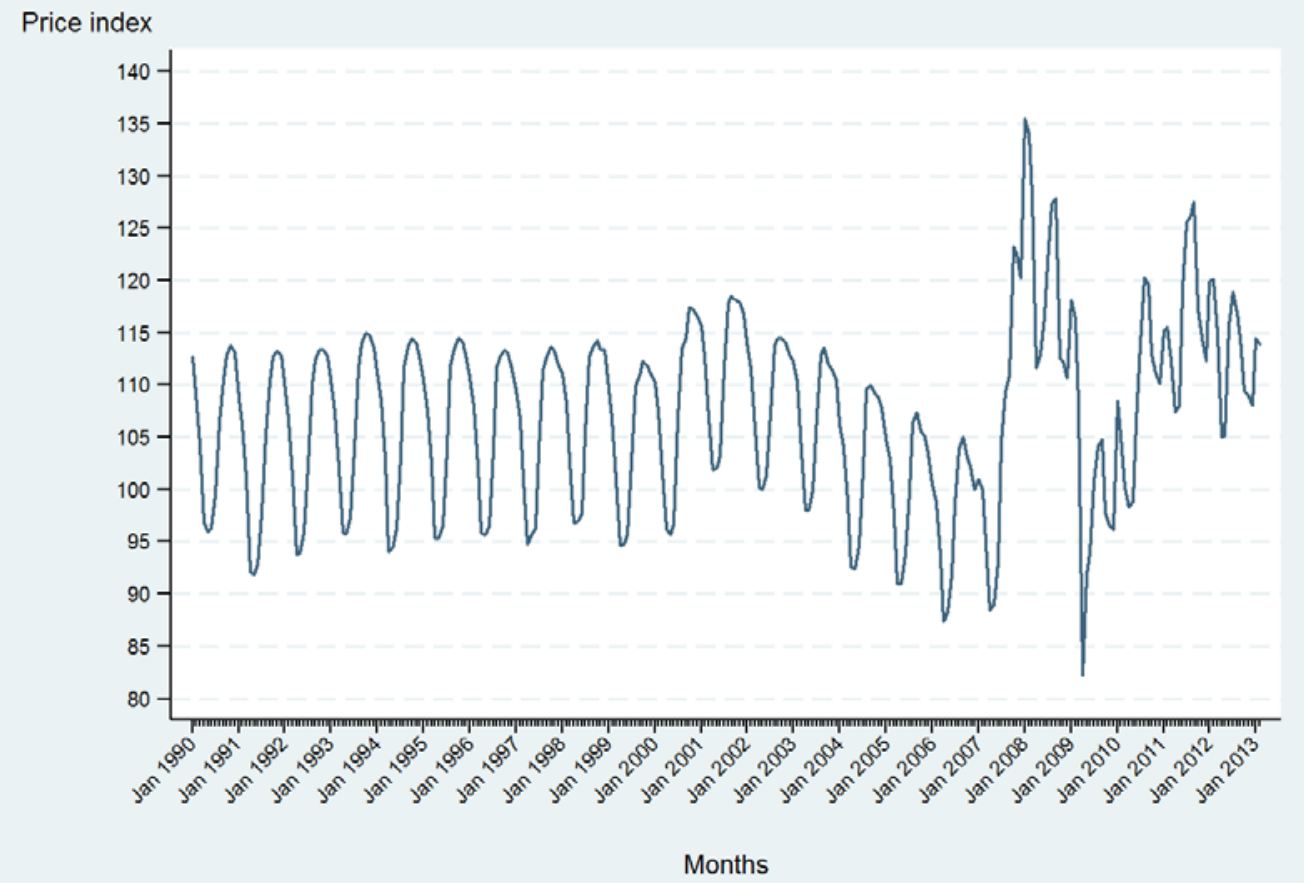

Figure 2: Evolution of prices 2006 - 2009

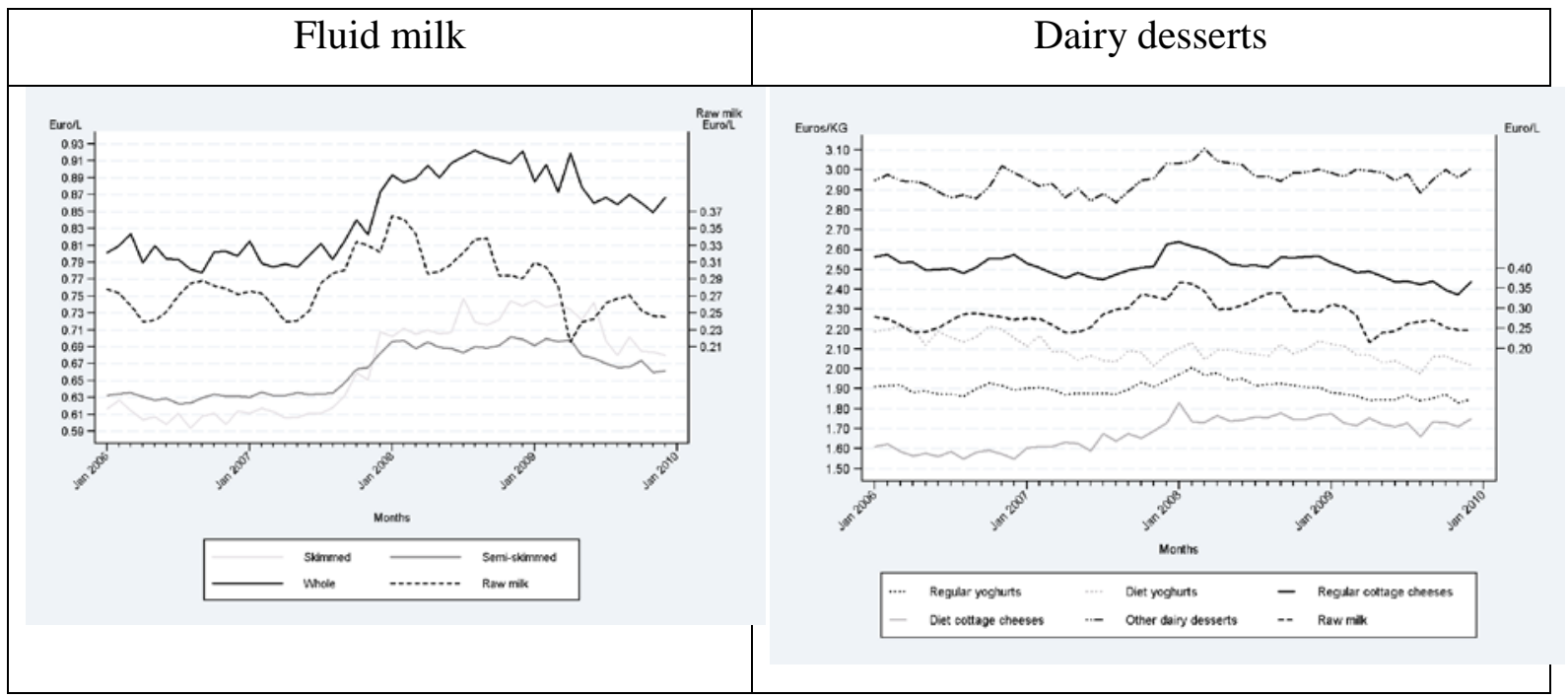


Table 1: Dairy desserts: descriptive statistics for prices and market shares by categories

\begin{tabular}{lcccccc}
\hline & \multicolumn{3}{c}{$\begin{array}{c}\text { Mean prices } \\
(€ \text { per litre) }\end{array}$} & \multicolumn{3}{c}{$\begin{array}{c}\text { Market shares } \\
(\%)\end{array}$} \\
\hline & NBs & PLs & All & NBs & PLs & All \\
\hline Regular yoghurts & 2.33 & 1.45 & 1.90 & 23.0 & 21.7 & 44.7 \\
Diet yoghurts & 2.46 & 1.46 & 2.10 & 8.4 & 4.7 & 13.0 \\
Regular cottage cheeses & 3.05 & 2.00 & 2.51 & 7.9 & 8.2 & 16.1 \\
Diet cottage cheeses & & 1.68 & 1.68 & & 2.1 & 2.1 \\
Regular forms of other dairy & 3.48 & 2.47 & 2.96 & 11.7 & 12.3 & 24.0 \\
Alll products & 2.72 & 1.81 & 2.27 & 50.9 & 49.1 & 100 \\
\hline
\end{tabular}

Table 2: Fluid milk: descriptive statistics for prices and market shares by categories

\begin{tabular}{lcccccc}
\hline & \multicolumn{3}{c}{$\begin{array}{c}\text { Mean prices } \\
\text { (€ }\end{array}$} & \multicolumn{3}{c}{$\begin{array}{c}\text { Market litre) } \\
\text { (\%) }\end{array}$} \\
\hline & NBs & PLs & All & NBs & PLs & All \\
\hline Skimmedmilk & 0.92 & 0.58 & 0.67 & 2.1 & 6.4 & 8.5 \\
Semi-skimmed milk & 0.71 & 0.63 & 0.66 & 34.1 & 51.7 & 85.8 \\
Whole milk & 1.07 & 0.73 & 0.84 & 2.0 & 3.8 & 5.8 \\
All products & 0.74 & 0.63 & 0.67 & 38.2 & 61.8 & 100 \\
\hline
\end{tabular}


Table 3: Results of the random coefficients logit model

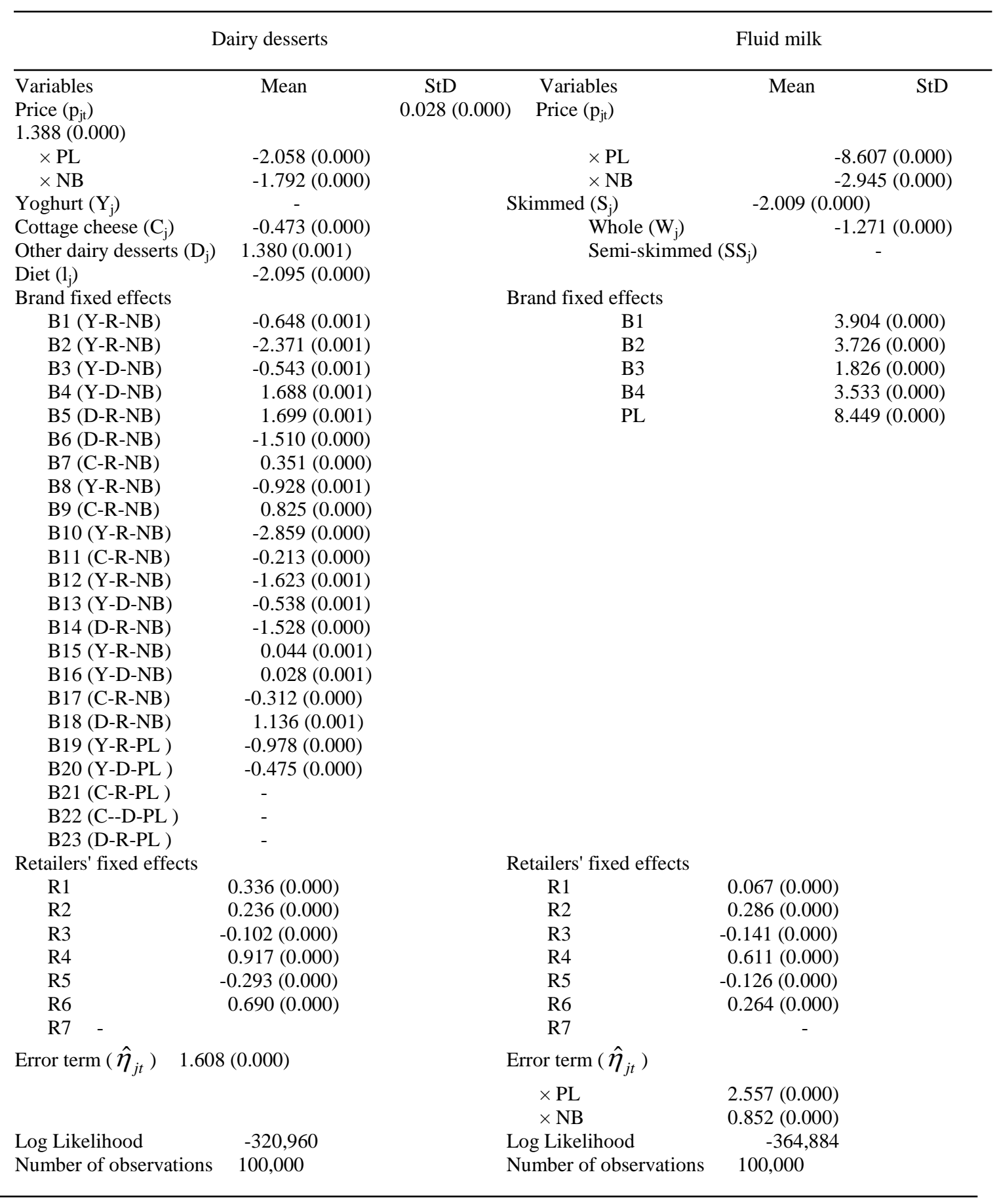

Standard errors are in parentheses. 


\section{Table 4: Average own-price elasticities between products}

\begin{tabular}{|c|c|c|c|c|}
\hline & \multicolumn{2}{|c|}{ Dairy desserts } & \multicolumn{2}{|c|}{ Fluid milk } \\
\hline Brands & Characteristic & Own-price elasticities & Characteristic & Own-price elasticities \\
\hline B1 & Y-R-NB & $-4.25(0.31)$ & S-NB & $-2.25(0.29)$ \\
\hline B2 & Y-R-NB & $-3.82(0.29)$ & SS-NB & $-2.21(0.14)$ \\
\hline B3 & Y-D-NB & $-3.72(0.32)$ & W-NB & $-2.43(0.09)$ \\
\hline B4 & Y-D-NB & $-4.81(0.44)$ & S-NB & $-2.41(0.13)$ \\
\hline B5 & D-R-NB & $-8.27(0.84)$ & SS-NB & $-2.24(0.15)$ \\
\hline B6 & D-R-NB & $-4.82(0.53)$ & W-NB & $-2.45(0.10)$ \\
\hline B7 & C-R-NB & $-5.73(0.54)$ & S-NB & $-2.37(0.12)$ \\
\hline B8 & Y-R-NB & $-4.10(0.56)$ & SS-NB & $-2.35(0.12)$ \\
\hline B9 & C-R-NB & $-5.79(0.44)$ & W-NB & $-2.38(0.13)$ \\
\hline B10 & Y-R-NB & $-3.22(0.26)$ & S-NB & $-1.81(0.23)$ \\
\hline B11 & C-R-NB & $-4.98(0.23)$ & SS-NB & $-1.79(0.09)$ \\
\hline B12 & Y-R-NB & $-4.63(0.50)$ & W-NB & $-2.27(0.20)$ \\
\hline B13 & Y-D-NB & $-3.95(0.52)$ & S-PL & $-5.47(0.58)$ \\
\hline B14 & D-R-NB & $-5.83(0.86)$ & SS-PL & $-5.16(0.50)$ \\
\hline B15 & Y-R-NB & $-5.37(1.33)$ & W-PL & $-6.56(0.71)$ \\
\hline B16 & Y-D-NB & $-4.50(1.06)$ & & \\
\hline B17 & C-R-NB & $-5.40(0.87)$ & & \\
\hline B18 & D-R-NB & $-7.53(1.75)$ & & \\
\hline B19 & Y-R-PL & $-2.97(0.16)$ & & \\
\hline B20 & Y-D-PL & $-3.03(0.17)$ & & \\
\hline B21 & C-R-PL & $-4.11(0.22)$ & & \\
\hline B22 & C-D-PL & $-3.53(0.47)$ & & \\
\hline B23 & D-R-PL & $-5.19(0.59)$ & & \\
\hline
\end{tabular}

Dairy desserts: Y/C/D stands for Yoghurt/Cottage cheese/Other dairy desserts;

R/D stands for Regular/Diet; NB/PL stands for National Brands/Private Labels.

Fluid milk: S/SS/W stands for Skimmed/Semi-skimmed/Whole milk. 
Table 5: Impact of a $\mathbf{1 0 \%}$ decrease in the raw milk price on retail prices

\begin{tabular}{|c|c|c|c|c|c|c|c|c|c|}
\hline & \multicolumn{4}{|c|}{ Dairy desserts } & \multicolumn{5}{|c|}{ Fluid milk } \\
\hline & & $\begin{array}{l}\text { Change in cost } \\
\text { in \% } \\
\text { Mean (std) }\end{array}$ & $\begin{array}{l}\text { Change in price } \\
\text { in \% } \\
\text { Mean (std) }\end{array}$ & $\begin{array}{c}\text { Pass-through } \\
\Delta \mathrm{p} / \Delta \mathrm{c} \\
\text { Mean (std) }\end{array}$ & & & $\begin{array}{l}\text { Change in cost } \\
\text { in \% } \\
\text { Mean (std) }\end{array}$ & $\begin{array}{l}\text { Change in price } \\
\text { in \% } \\
\text { Mean (std) }\end{array}$ & $\begin{array}{c}\text { Pass-through } \\
\Delta \mathrm{p} / \Delta \mathrm{c} \\
\text { Mean (std) }\end{array}$ \\
\hline Brand 1 & Y-R-NB & $-2.09(0.26)$ & $-1.13(0.12)$ & $0.82(0.00)$ & Brand 1 & S-NB & $-2.88(2.92)$ & $-1.45(0.41)$ & $1.12(0.23)$ \\
\hline Brand 2 & Y-R-NB & $-2.34(0.33)$ & $-1.34(0.17)$ & $0.86(0.01)$ & Brand 2 & SS-NB & -3.18 & $0.64) \quad-1.69(0$ & $0.25) \quad 1.09(0.02)$ \\
\hline Brand 3 & Y-D-NB & $-1.23(0.23)$ & $-0.58(0.09)$ & $0.73(0.01)$ & Brand 3 & W-NB & $-4.48(0.77)$ & $-3.14(0.42)$ & $1.30(0.04)$ \\
\hline Brand 4 & Y-D-NB & $-0.88(0.17)$ & $-0.39(0.06)$ & $0.63(0.00)$ & Brand 4 & S-NB & $-2.27(0.52)$ & $-1.28(0.25)$ & $1.04(0.04)$ \\
\hline Brand 5 & D-R-NB & $-0.35(0.05)$ & $-0.21(0.03)$ & $0.72(0.02)$ & Brand 5 & SS-NB & -3.00 & $0.75) \quad-1.58(0$ & $0.28) \quad 1.05(0.03)$ \\
\hline Brand 6 & D-R-NB & $-0.73(0.13)$ & $-0.28(0.04)$ & $0.55(0.01)$ & Brand 6 & W-NB & $-4.05(0.79)$ & $-2.95(0.40)$ & $1.33(0.08)$ \\
\hline Brand 7 & C-R-NB & $-1.58(0.21)$ & $-0.99(0.12)$ & $0.84(0.00)$ & Brand 7 & S-NB & $-2.55(0.51)$ & $-1.44(0.24)$ & $1.06(0.02)$ \\
\hline Brand 8 & Y-R-NB & $-2.27(0.43)$ & $-1.19(0.18)$ & $0.82(0.00)$ & Brand 8 & SS-NB & -2.58 & $0.43) \quad-1.44(0$ & $0.21) \quad 1.06(0.02)$ \\
\hline Brand 9 & C-R-NB & $-1.55(0.20)$ & $-0.98(0.12)$ & $0.84(0.00)$ & Brand 9 & W-NB & $-5.04(1.57)$ & $-3.33(0.59)$ & $1.25(0.03)$ \\
\hline Brand 10 & Y-R-NB & $-3.07(0.46)$ & $-1.59(0.20)$ & $0.86(0.01)$ & Brand 10 & S-NB & $-7.84(2.81)$ & $-2.71(0.61)$ & $1.22(0.08)$ \\
\hline Brand 11 & C-R-NB & $-1.82(0.23)$ & $-1.19(0.15)$ & $0.88(0.01)$ & Brand 11 & SS-NB & $-7.02(1.30)$ & $-2.71(0.37)$ & $1.22(0.05)$ \\
\hline Brand 12 & Y-R-NB & $-1.80(0.31)$ & $-1.14(0.16)$ & $0.88(0.01)$ & Brand 12 & W-NB & $-6.79(2.89)$ & $-3.83(0.72)$ & $1.28(0.05$ \\
\hline Brand 13 & Y-D-NB & $-1.16(0.33)$ & $-0.58(0.11)$ & $0.77(0.02)$ & Brand 13 & S-PL & $-2.62(0.44)$ & $-2.02(0.26)$ & $0.97(0.01)$ \\
\hline Brand 14 & D-R-NB & $-0.55(0.11)$ & $-0.30(0.05)$ & $0.72(0.02)$ & Brand 14 & SS-PL & $-2.57(0.35)$ & $-1.99(0.24)$ & $0.97(0.01)$ \\
\hline Brand 15 & Y-R-NB & $-1.86(1.37)$ & $-1.05(0.45)$ & $0.87(0.01)$ & Brand 15 & W-PL & $-4.13(0.78)$ & $-3.41(0.52)$ & $1.00(0.01)$ \\
\hline Brand 16 & Y-D-NB & $-1.17(0.86)$ & $-0.52(0.20)$ & $0.73(0.02)$ & & & & & \\
\hline Brand 17 & C-R-NB & $-1.75(0.55)$ & $-1.14(0.26)$ & $0.88(0.01)$ & & & & & \\
\hline Brand 18 & D-R-NB & $-0.45(0.23)$ & $-0.23(0.09)$ & $0.67(0.02)$ & & & & & \\
\hline Brand 19 & Y-R-PL & $-3.48(0.46)$ & $-2.23(0.27)$ & $0.98(0.01)$ & & & & & \\
\hline Brand 20 & Y-D-PL & $-1.70(0.25)$ & $-1.08(0.14)$ & $0.97(0.01)$ & & & & & \\
\hline Brand 21 & C-R-PL & $-2.51(0.30)$ & $-1.85(0.21)$ & $0.99(0.01)$ & & & & & \\
\hline Brand 22 & C-D-PL & $-2.66(0.49)$ & $-1.83(0.28)$ & $0.98(0.01)$ & & & & & \\
\hline Brand 23 & D-R-PL & $-0.67(0.11)$ & $-0.52(0.08)$ & $0.96(0.01)$ & & & & & \\
\hline
\end{tabular}


Table 6: Regression of pass-through on cost shock variables and product characteristics

\begin{tabular}{|c|c|c|}
\hline & Model 1 & Model 2 \\
\hline Retailer 1 & $0.01(0.00)^{* * *}$ & \\
\hline Retailer 2 & $0.03(0.00)^{* * *}$ & \\
\hline Retailer 3 & $0.02(0.00)^{* * *}$ & \\
\hline Retailer 4 & $0.02(0.00)^{* * *}$ & \\
\hline Retailer 5 & $0.03(0.00)^{* * *}$ & \\
\hline Retailer 6 & $0.02(0.00)^{* * *}$ & \\
\hline Retailer 7 & - & \\
\hline \multicolumn{3}{|l|}{ Fluid milk manufacturers } \\
\hline Manufacturer 1 & \multicolumn{2}{|l|}{$-0.07(0.00)^{* * *}$} \\
\hline Manufacturer 2 & \multicolumn{2}{|l|}{$-0.10(0.00) * * *$} \\
\hline Manufacturer 3 & & \\
\hline \multicolumn{3}{|l|}{ Dairy desserts manufacturers } \\
\hline Manufacturer 4 & \multicolumn{2}{|l|}{$-0.49(0.00)^{* * *}$} \\
\hline Manufacturer 5 & \multicolumn{2}{|l|}{$-0.40(0.00)^{* * *}$} \\
\hline Manufacturer 6 & \multicolumn{2}{|l|}{$-0.46(0.00)^{* * *}$} \\
\hline Manufacturer 7 & \multicolumn{2}{|l|}{$-0.45(0.00) * * *$} \\
\hline Private labels & \multicolumn{2}{|l|}{$-0.25(0.00)^{* * *}$} \\
\hline Private labels (fluid Milk) & $0.00(0.00)$ & \\
\hline Fluid milk market & \multicolumn{2}{|r|}{$0.54(0.05)^{* * *}$} \\
\hline Manufacturer market shares & & $-0.54(0.05)^{* * *}$ \\
\hline Retailer market shares & & $-0.28(0.06)^{* * *}$ \\
\hline Private label shares & & $-0.49(0.13) * * *$ \\
\hline Private label shares for PL & & $0.34(0.04)^{* * *}$ \\
\hline Const & $1.19(0.00)$ & $1.01(0.04)^{* * *}$ \\
\hline Period fixed effects & Yes & Yes \\
\hline R-square & 0.78 & 0.60 \\
\hline
\end{tabular}

Standard errors are in parenthesis. 


\section{APPENDICES}

Table 7: Dairy desserts: descriptive statistics for prices and market shares by brands.

\begin{tabular}{|c|c|c|c|c|c|}
\hline & & & $\begin{array}{l}\text { Number of } \\
\text { ers }\end{array}$ & $\begin{array}{r}\text { Prices } \\
\text { Mean (std) }\end{array}$ & $\begin{array}{l}\text { Market shares } \\
\text { Mean in \% (std) }\end{array}$ \\
\hline National Brands & & & 7 & $2.72(0.08)$ & $50.94(1.31)$ \\
\hline Brand 1 & Y-R & 7 & & $2.42(0.11)$ & $6.83(0.64)$ \\
\hline Brand 2 & $\mathrm{Y}-\mathrm{R}$ & 7 & & $2.10(0.07)$ & $2.15(0.19)$ \\
\hline Brand 3 & $Y-D$ & 7 & & $2.07(0.08)$ & $1.74(0.24)$ \\
\hline Brand 4 & Y-D & 7 & & $2.75(0.11)$ & $4.27(0.27)$ \\
\hline Brand 5 & D-R & 7 & & $4.57(0.19)$ & $2.27(0.44)$ \\
\hline Brand 6 & D-R & 7 & & $2.70(0.21)$ & $4.64(0.41)$ \\
\hline Brand 7 & C-R & 7 & & $3.25(0.19)$ & $1.75(0.18)$ \\
\hline Brand 8 & $\mathrm{Y}-\mathrm{R}$ & & 7 & $2.25(0.17)$ & $7.03(0.64)$ \\
\hline Brand 9 & C-R & 6 & & $3.25(0.12)$ & $2.21(0.29)$ \\
\hline Brand 10 & $\mathrm{Y}-\mathrm{R}$ & 6 & 5 & $1.81(0.06)$ & $2.18(0.31)$ \\
\hline Brand 11 & C-R & 7 & 7 & $2.78(0.08)$ & $2.64(0.21)$ \\
\hline Brand 12 & $\mathrm{Y}-\mathrm{R}$ & 7 & & $2.61(0.13)$ & $1.59(0.23)$ \\
\hline Brand 13 & Y-D & 7 & 7 & $2.22(0.09)$ & $1.20(0.31)$ \\
\hline Brand 14 & D-R & 7 & & $3.10(0.15)$ & $1.50(0.13)$ \\
\hline Brand 15 & $\mathrm{Y}-\mathrm{R}$ & 7 & & $2.74(0.07)$ & $3.23(0.23)$ \\
\hline Brand 16 & Y-D & 7 & & $2.28(0.19)$ & $1.15(0.29)$ \\
\hline Brand 17 & C-R & 7 & & $2.99(0.07)$ & $1.30(0.16)$ \\
\hline Brand 18 & D-R & 7 & & $4.03(0.21)$ & $3.26(0.19)$ \\
\hline Private Labels & & 7 & & $1.81(0.05)$ & 49.06 (1.31) \\
\hline Brand 19 & Y-R & 7 & & $1.45(0.03)$ & $21.73(0.57)$ \\
\hline Brand 20 & Y-D & 7 & & $1.46(0.02)$ & $4.64(0.36)$ \\
\hline Brand 21 & C-R & 7 & & $2.00(0.05)$ & $8.23(0.37)$ \\
\hline Brand 22 & C-D & 7 & 7 & $1.68(0.07)$ & $2.14(0.26)$ \\
\hline Brand 23 & $\mathrm{D}-\mathrm{R}$ & 7 & 7 & $2.47(0.08)$ & $12.32(0.39)$ \\
\hline
\end{tabular}

Y stands for yoghurt, $\mathrm{C}$ for cottage cheese, D for other dairy desserts, R for regular and D for diet.

Standard deviations are in parenthesis.

Prices are in euros/kilogram.

Table 8: Dairy desserts: descriptive statistics for prices and market shares by retailers.

\begin{tabular}{|c|c|c|c|c|c|c|}
\hline & \multirow{2}{*}{\multicolumn{2}{|c|}{$\begin{array}{l}\text { Number of brands } \\
\text { NB }\end{array}$}} & \multirow{2}{*}{$\begin{array}{l}\text { Share of PL } \\
\text { PL }\end{array}$} & Price of NB & Price of PL Price & \multirow{2}{*}{$\begin{array}{r}\text { Market shares } \\
\text { Mean in \% }\end{array}$} \\
\hline & & & & $\% \quad$ Mean & Mean Mean & \\
\hline Retailer 1 & 18 & 5 & 46.95 (2.27) & $2.64(0.09)$ & $1.74(0.05) 2.22(0.04)$ & $17.45(0.49)$ \\
\hline Retailer 2 & 18 & 5 & 53.48 (2.29) & $2.76(0.11)$ & $1.85(0.07) 2.27(0.04)$ & $13.60(0.20)$ \\
\hline Retailer 3 & 18 & 5 & $34.53(2.23)$ & $2.71(0.09)$ & $1.77(0.06) 2.39(0.05)$ & $10.52(0.24)$ \\
\hline Retailer 4 & 18 & 5 & $37.69(2.13)$ & $2.81(0.09)$ & $1.84(0.05) 2.44(0.05)$ & $20.94(0.55)$ \\
\hline Retailer 5 & 18 & 5 & $42.52(1.32)$ & $2.69(0.10)$ & $1.83(0.05) 2.32(0.06)$ & $7.87(0.27)$ \\
\hline Retailer 6 & 18 & 5 & $38.22(2.02)$ & $3.02(0.10)$ & $2.03(0.09) 2.64(0.05)$ & $12.41(0.39)$ \\
\hline Retailer 7 & 16 & 5 & 81.34 (3.33) & $1.90(0.09)$ & $1.73(0.05) 1.77(0.05)$ & $17.20(0.75)$ \\
\hline
\end{tabular}

Standard deviations are in parenthesis, prices are in euros/kilogram. 
Table 9: Fluid milk: descriptive statistics for prices and market shares by brands.

\begin{tabular}{cllccc}
\hline & \multicolumn{2}{c}{ Type } & Number of & Prices & Market shares \\
& & Retailers & Mean & Mean in \% \\
National Brands & & & 7 & $0.74(0.02)$ & $38.16(3.43)$ \\
Brand 1 & S & 7 & $0.95(0.17)$ & $0.88(0.14)$ \\
Brand 2 & SS & 7 & $0.83(0.05)$ & $8.94(1.31)$ \\
Brand 3 & W & 7 & $1.13(0.08)$ & $0.72(0.10)$ \\
Brand 4 & S & 7 & $1.07(0.09)$ & $0.82(0.10)$ \\
Brand 5 & SS & 7 & $0.86(0.05)$ & $7.44(1.25)$ \\
Brand 6 & W & 7 & $1.16(0.10)$ & $0.62(0.07)$ \\
Brand 7 & S & 5 & $0.98(0.07)$ & $0.02(0.02)$ \\
Brand 8 & SS & 7 & $0.94(0.07)$ & $0.41(0.07)$ \\
Brand 9 & W & 7 & $1.01(0.07)$ & $0.17(0.03)$ \\
Brand 10 & S & 7 & $0.54(0.03)$ & $0.35(0.12)$ \\
Brand 11 & SS & 7 & $0.57(0.01)$ & $17.34(1.97)$ \\
Brand 12 & W & 7 & $0.89(0.06)$ & $0.45(0.06)$ \\
Private Labels & & 7 & $0.63(0.03)$ & $61.84(3.43)$ \\
Brand 13 & S & 7 & $0.58(0.04)$ & $6.38(0.30)$ \\
Brand 14 & SS & 7 & $0.63(0.03)$ & $51.66(3.47)$ \\
Brand 15 & W & 7 & \multicolumn{2}{c}{$0.73(0.04)$} & $3.80(0.28)$ \\
\hline
\end{tabular}

S stands for skimmed, SS for semi-skimmed, W for whole milk.

Standard deviations are in parenthesis.

Prices are in euros/kilogram.

Table 10: Fluid milk: descriptive statistics for prices and market shares by retailers.

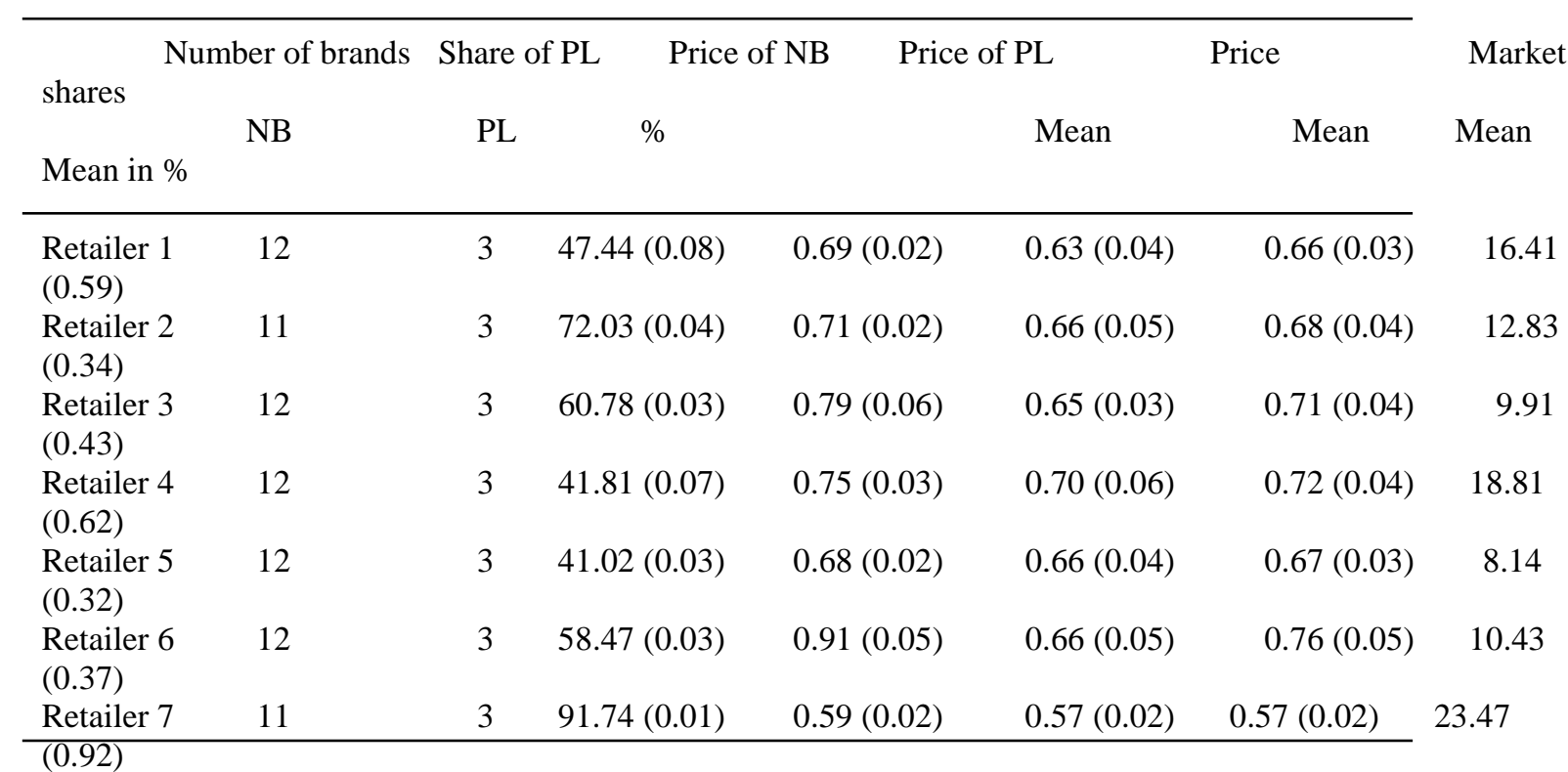

Standard deviations are in parenthesis.

Prices are in euros/kilogram. 
Table 11: Results on price equation

\begin{tabular}{|c|c|c|c|}
\hline Coeff & $\begin{array}{l}\text { Dairy desserts } \\
\text { cient (Standard Error) }\end{array}$ & \multicolumn{2}{|c|}{$\begin{array}{c}\text { Fluid milk } \\
\text { Coefficient (Standard Error) }\end{array}$} \\
\hline Cow milk & $0.730 * * *(0.361)$ & Cow milk & $0.751 * * *(0.248)$ \\
\hline Cow milk x PL & $-0.172(0.775)$ & Cow milk x PL & $-0.227(0.528)$ \\
\hline Wage & $-0.067 * * *(0.016)$ & Wage & $-0.080 * * *(0.008)$ \\
\hline $\begin{array}{l}\text { Wage x PL } \\
(0.010)\end{array}$ & $0.085 * * *(0.033)$ & Wage x M2 & $-0.040 * * *$ \\
\hline $\begin{array}{l}\text { Aluminium } \\
(0.011)\end{array}$ & $0.001(0.001)$ & Wage x M3 & $-0.081 * * *$ \\
\hline $\begin{array}{l}\text { Aluminium x PL } \\
(0.012)\end{array}$ & $-0.000(0.003)$ & Wage x M4 & $-0.054 * * *$ \\
\hline Gazole & $-0.002 * * *(0.001)$ & Gazole & $-0.001 * * *(0.000)$ \\
\hline $\begin{array}{l}\text { Gazole x PL } \\
(0.001)\end{array}$ & $0.002(0.003)$ & Gazole x PL & -0.000 \\
\hline Glass & $0.015 * * *(0.005)$ & Cardboard & $-0.005 * * *(0.002)$ \\
\hline Glass x PL & $-0.005(0.010)$ & Cardboard x PL & $0.005(0.005)$ \\
\hline Metal & $-0.025 * * *(0.009)$ & & \\
\hline Metal x PL & $0.017(0.019)$ & & \\
\hline Cottage cheese & $-0.262(2.694)$ & Skimmed milk & $0.104 * * *(0.012)$ \\
\hline $\begin{array}{l}\text { Other dairy desserts } \\
(0.012)\end{array}$ & $0.282(2.694)$ & Whole milk & $0.214^{* * *}$ \\
\hline Diet & $-0.294 * * *(0.047)$ & & \\
\hline Product fixed effects & $167.68 * * *(0.000)$ & Brand fixed effects & $20.51 * * *(0.000)$ \\
\hline $\begin{array}{l}\text { Retailers fixed effects } \\
28.99 * * *(0.000)\end{array}$ & $87.37 * * *(0.000)$ & Retailers fixed effects & \\
\hline R-squared & 0.984 & R-squared & 0.960 \\
\hline Number of observations & 2574 & Number of observations & 1514 \\
\hline
\end{tabular}

*** significant at 5\%; M2,M3 and M4 stand for Manufacturer 2, 3 and 4;

Standard errors are in parenthesis for all coefficients except for fixed effects where p-values are in parenthesis. 
Table 12: Margins for the preferred model (dairy desserts)

\begin{tabular}{|c|c|c|c|c|c|}
\hline \multicolumn{3}{|c|}{ By brands } & \multicolumn{3}{|c|}{ By retailers } \\
\hline & Total margins & Total marginal costs & & Total margins & Total marginal \\
\hline Brands & in $\%$ & in euros & Retailers & in \% & in euros \\
\hline B1 & 33.48 (2.62) & $1.59(0.18)$ & R1 & 29.16 (6.66) & $1.83(0.73)$ \\
\hline B2 & 33.38 (2.57) & $1.43(0.16)$ & R2 & 27.55 (6.59) & $1.97(0.76)$ \\
\hline B3 & $34.43(3.20)$ & $1.37(0.18)$ & R3 & $28.84(6.45)$ & $1.84(0.72)$ \\
\hline B4 & $29.74(3.07)$ & $1.90(0.24)$ & $\mathrm{R} 4$ & $27.50(6.92)$ & $2.03(0.88)$ \\
\hline B5 & $15.61(1.46)$ & $3.92(0.46)$ & R5 & $28.27(6.45)$ & $1.90(0.74)$ \\
\hline B6 & $29.72(3.08)$ & $1.91(0.29)$ & R6 & 25.47 (6.05) & $2.20(0.87)$ \\
\hline B7 & $24.99(2.52)$ & $2.41(0.30)$ & R7 & 32.77 (10.14) & $1.63(0.90)$ \\
\hline B8 & 35.13 (4.35) & $1.50(0.32)$ & & & \\
\hline B9 & $24.64(2.11)$ & $2.45(0.25)$ & & & \\
\hline B10 & $39.65(3.00)$ & $1.09(0.14)$ & & & \\
\hline B11 & $25.53(1.10)$ & $2.07(0.12)$ & & & \\
\hline B12 & $28.03(3.16)$ & $1.87(0.28)$ & & & \\
\hline B13 & 33.11 (4.94) & $1.49(0.29)$ & & & \\
\hline B14 & $22.38(2.72)$ & $2.54(0.48)$ & & & \\
\hline B15 & $26.82(11.01)$ & $2.28(0.75)$ & & & \\
\hline B16 & 31.45 (11.16) & $1.79(0.59)$ & & & \\
\hline B17 & $24.91(5.03)$ & $2.29(0.49)$ & & & \\
\hline B18 & $18.77(6.76)$ & $3.49(0.98)$ & & & \\
\hline B19 & 34.63 (1.91) & $0.95(0.08)$ & & & \\
\hline B20 & 34.20 (2.13) & $0.97(0.08)$ & & & \\
\hline B21 & 25.13 (1.43) & $1.51(0.11)$ & & & \\
\hline B22 & $29.81(3.64)$ & $1.21(0.23)$ & & & \\
\hline B23 & $19.96(2.18)$ & $2.05(0.29)$ & & & \\
\hline
\end{tabular}

Standard deviations are in parenthesis.

Table 13: Margins for the preferred model (fluid milk)

\begin{tabular}{|c|c|c|c|c|c|c|}
\hline \multirow[b]{2}{*}{ Brands } & \multicolumn{2}{|c|}{ By brands } & \multicolumn{2}{|c|}{ By retailers } & \multicolumn{2}{|c|}{ Total marginal costs } \\
\hline & $\begin{array}{c}\text { Total margins } \\
\text { in } \%\end{array}$ & $\begin{array}{c}\text { Total marginal costs } \\
\text { in euros }\end{array}$ & Retailers & $\begin{array}{c}\text { Total margins } \\
\text { in } \%\end{array}$ & Total & $\begin{array}{l}\text { costs } \\
\text { os }\end{array}$ \\
\hline B1 & 50.65 (9.97) & $0.45(0.26)$ & $\mathrm{R} 1$ & 45.76 & 15.79) & 0.43 \\
\hline B2 & $50.69(3.62)$ & $0.43(0.09)$ & $\mathrm{R} 2$ & 43.65 & 17.16) & 0.48 \\
\hline B3 & 45.77 (1.89) & $0.54(0.19)$ & R3 & 43.75 & 15.64) & 0.47 \\
\hline B4 & $45.62(2.83)$ & $0.53(0.22)$ & R4 & 44.96 & 15.54) & 0.46 \\
\hline B5 & $49.12(4.05)$ & $0.45(0.11)$ & R5 & 42.85 & 15.07) & 0.53 \\
\hline B6 & $44.56(1.93)$ & $0.58(0.26)$ & R6 & 43.20 & 14.52) & 0.52 \\
\hline B7 & $46.45(2.36)$ & $0.30(0.27)$ & R7 & 49.39 & 19.97) & 0.25 \\
\hline B8 & $46.82(2.44)$ & $0.51(0.11)$ & & & & \\
\hline B9 & 46.26 (3.18) & $0.46(0.22)$ & & & & \\
\hline B10 & 69.28 (8.27) & $0.19(0.14)$ & & & & \\
\hline B11 & 67.72 (3.90) & $0.19(0.03)$ & & & & \\
\hline B12 & $52.95(6.62)$ & $0.44(0.13)$ & & & & \\
\hline B13 & $20.23(2.91)$ & $0.51(0.07)$ & & & & \\
\hline B14 & $19.90(2.12)$ & $0.52(0.06)$ & & & & \\
\hline B15 & 16.87 (2.63) & $0.66(0.10)$ & & & & \\
\hline
\end{tabular}

Standard deviations are in parenthesis. 
Table 14: Estimation of the marginal cost function (preferred model)

\begin{tabular}{|c|c|c|c|}
\hline $\mathrm{C}_{\mathrm{jt}}$ & $\begin{array}{l}\text { Desserts } \\
\quad \text { Coefficient } \\
\text { (Standard error) }\end{array}$ & $\mathrm{C}_{\mathrm{jt}}$ & $\begin{array}{l}\text { uid Milk } \\
\text { Coefficient } \\
\text { (Standard error) }\end{array}$ \\
\hline Wages & $0.0057(0.0004)$ & Wages & $0.0015(0.0001)$ \\
\hline Plastic & $0.0004(0.0000)$ & Cardboard & $0.0004(0.0000)$ \\
\hline Energy & $0.0055(0.0006)$ & Energy & $0.0008(0.0001)$ \\
\hline Milk x D & $0.4776(0.0325)$ & Milk x Whole & $0.9352(0.0485)$ \\
\hline Milk x C x R & $1.3294(0.1258)$ & Milk x No Who & e 0.4621 (0.0555) \\
\hline Milk x C x L & $1.1082(0.3491)$ & & \\
\hline Milk x Y x R & 1.1644 (0.1733) & & \\
\hline Milk x Y x L & $0.5801(0.0605)$ & & \\
\hline \multirow{2}{*}{\multicolumn{2}{|c|}{$\begin{array}{l}\text { Coefficients } w_{b(j)}^{h} \text { and } w_{r(j)}^{h} \text { not shown } \\
\text { F test for } w_{b(j)}^{h} \text { (p value) } 564.10(0.00)\end{array}$}} & \multirow{2}{*}{\multicolumn{2}{|c|}{ Coefficients $w_{r(j)}^{h}$ not shown }} \\
\hline & & & \\
\hline \multicolumn{2}{|c|}{ F test for $w_{r(j)}^{h}$ (p value) $98.62(0.00)$} & \multicolumn{2}{|c|}{ F test for $w_{r(j)}^{h}$ (p value) $47.22(0.00$} \\
\hline
\end{tabular}

Table 15: Statistics $\mathbf{T}_{\mathbf{n}}$ of non-nested Rivers and Vuong tests

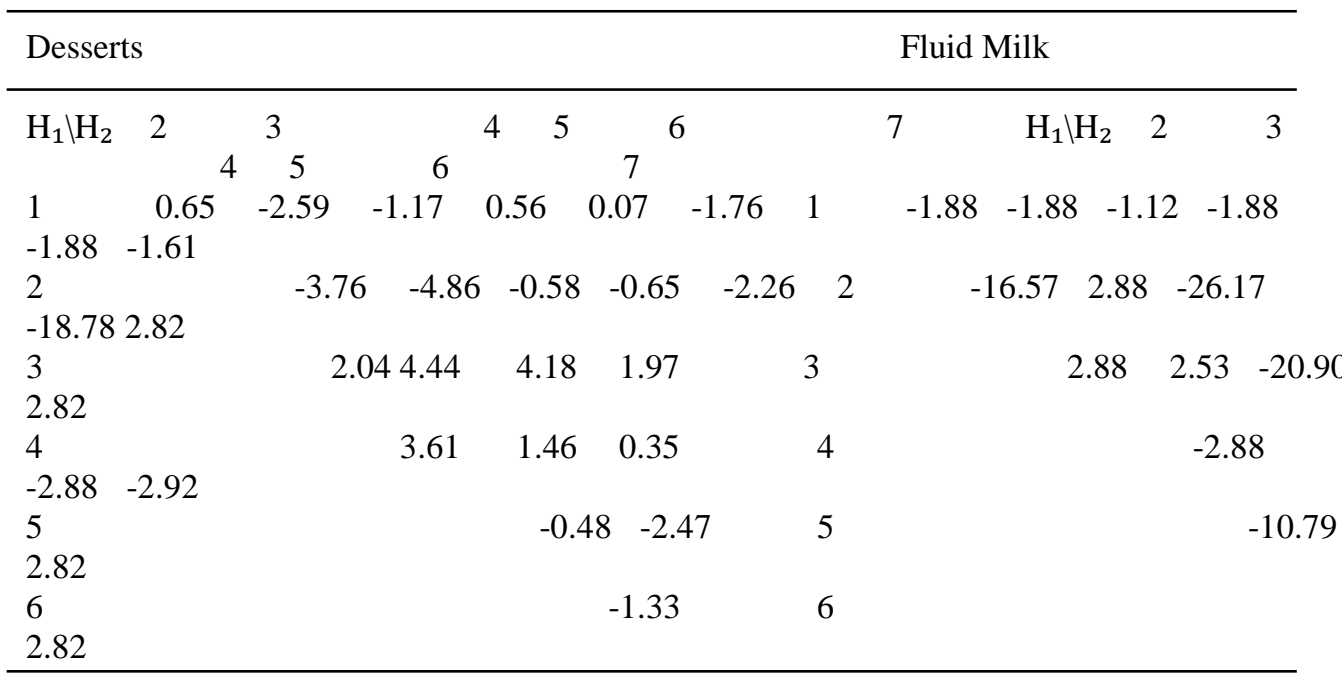

Model 1 is linear pricing

Model 2 is two part tariff with RPM and $w=\mu$

Model 3 is two part tariff with RPM and p-w-c=0

Model 4 is two part tariff without RPM

Model 5 is two part tariff with RPM, $w=\mu$ and private labels buyer power

Model 6 is two part tariff with RPM, p-w-c=0 and private labels buyer power

Model 7 is two part tariff without RPM and private labels buyer power

For the dessert market, consider row 3: all test statistics of the Rivers and Vuong test are higher than 1.96 which means that model 3 is better than models 4, 5, 6 or 7 .

In addition, the test statistics in column 3 is lower than -1.96 which means that models 1 and 2 are not preferred to model 3 . As a consequence model 3 is the preferred model.

For the fluid milk market, consider row 6: the test statistic of the Rivers and Vuong test is higher than 1.96 which means that model 6 is better than model 7. In addition, the test statistics in column 6 are lower than -1.96 (except for model 1) which means that models 2, 3, 4 and 5 are not preferred to model 6 . As regards the model 1, we consider that model 6 is preferred at a $10 \%$ threshold (the test statistic is lower than 1.64). As a consequence model 6 is the preferred model. 